\title{
Critical evaluation of paliperidone in the treatment of schizophrenia in Chinese patients: a systematic literature review
}

This article was published in the following Dove Press journal:

Neuropsychiatric Disease and Treatment

II January 2016

Number of times this article has been viewed

\section{LiLi Zhang' \\ JiTao $\mathrm{Li}^{2-4}$ \\ Yanjie Zhao ${ }^{5}$ \\ Yun'Ai Su ${ }^{2-4}$}

Tianmei $\mathrm{Si}^{2-4}$

'Medical Affairs, Xian Janssen Pharmaceutical Co, Ltd, ${ }^{2}$ National Clinical Research Center for Mental Disorders, ${ }^{3}$ Peking University Sixth Hospital, Institute of Mental Health, ${ }^{4}$ The Key Laboratory of Mental Health, Ministry of Health, Peking University, ${ }^{5}$ National Institute for Nutrition and Health, Chinese Center for Disease Control and Prevention, Beijing, People's Republic of China
Correspondence: Tianmei $\mathrm{Si}$ National Clinical Research Center for Mental Disorders, Peking University Sixth Hospital, Institute of Mental Health, Huayuanbeilu 5I, Haidian District, Beijing 100191, People's Republic of China

Tel +86 I0 62723748

Fax +86 I0 62027314

Email si.tian-mei@।63.com
Background: Paliperidone (9-hydroxyrisperidone), the major active metabolite of risperidone, has been introduced as a novel atypical antipsychotic agent in many countries. It is available both as an oral extended-release (ER) formulation and as a long-acting injection (paliperidone palmitate, PP), which have been approved for treating schizophrenia in the People's Republic of China since 2009 and 2012, respectively. This systematic review summarizes the efficacy, effectiveness, and safety of paliperidone in the treatment of schizophrenia in the Chinese population.

Methods: A systematic literature search was conducted on the databases covering international and Chinese core journals, published from January 1, 2008, to May 22, 2015.

Results: A total of 122 publications were retrieved, of which 63 studies were identified for inclusion; most studies were related to paliperidone ER $(n=53)$, nine were related to PP, and one study was related to both agents. Paliperidone ER demonstrated at least comparable efficacy with active comparators, including risperidone, olanzapine, ziprasidone, or aripiprazole, and was found to be superior with respect to the onset of action and improvement in the Personal and Social Performance Scale score. Paliperidone ER appeared to be associated with a lower risk of metabolic syndromes; the most common treatment-emergent adverse events were extrapyramidal symptoms, akathisia, insomnia, and somnolence. Results from interventional and observational studies showed that PP was also an effective and well-tolerated treatment for Chinese patients with schizophrenia. The findings were generally consistent with those observed in non-Chinese populations.

Conclusion: Both paliperidone ER and PP were effective and well-tolerated agents for the treatment of schizophrenia in the Chinese population according to the data we reviewed. No new safety signals specific for the Chinese population were raised for paliperidone. Further studies may be needed to collect more data on long-term treatment of schizophrenia in the People's Republic of China.

Keywords: paliperidone, antipsychotics, efficacy, effectiveness, safety

\section{Introduction}

Schizophrenia is one of the most common psychotic disorders. The 1-month prevalence of schizophrenia in the mainland Chinese population is $0.78 \%$ according to an epidemiologic study conducted in four provinces. ${ }^{1}$ Antipsychotics have been the mainstay of treatment for schizophrenia.

Paliperidone, also referred to as 9-hydroxyrisperidone, is the major active metabolite of risperidone. ${ }^{2}$ The mechanism of action of paliperidone is unknown; however, it is known that it acts as an antagonist at dopamine-2 $\left(\mathrm{D}_{2}\right)$ receptors and 5-hydroxytryptamine $2 \mathrm{~A}\left(5-\mathrm{HT}_{2 \mathrm{~A}}\right)$ receptors, with a higher affinity for $5-\mathrm{HT}_{2 \mathrm{~A}}$ receptors 
than for $\mathrm{D}_{2}$ receptors. In addition, paliperidone also acts as an antagonist at $\alpha_{1}$-adrenoceptors, and binds with lower affinity to $\alpha_{2}$-adrenoceptors and histamine- 1 receptors. It has no affinity for cholinergic muscarinic receptors. ${ }^{3}$ Paliperidone is available as two extended-release (ER) formulations: an osmotic-controlled-release oral delivery system (Paliperidone $\mathrm{ER}$, Invega), and an injectable suspension formulation of paliperidone palmitate (PP, Sustenna ${ }^{\circledR}$ ). Paliperidone ER utilizes osmotic-controlled-release oral delivery system (OROS ${ }^{\circledR}$ ) technology to provide sustained release over a 24-hour period, thereby reducing fluctuations in peak and trough plasma concentrations. ${ }^{4}$ It is administered once daily without initial dose titration, and was introduced in the People's Republic of China in 2009 for the treatment of schizophrenia. PP is the first monthly long-acting injectable atypical antipsychotic agent in the People's Republic of China. ${ }^{5}$ It was marketed in 2012, also indicated for schizophrenia. At present, these two formulations of paliperidone are in wide use in clinical practice in the People's Republic of China.

There have been some studies evaluating the pharmacokinetic characteristics and clinical profiles of both paliperidone formulations in the Chinese population. The aim of our systematic review is to summarize the clinical evidence of the pharmacokinetic characteristics, efficacy, effectiveness, and safety of paliperidone in treating schizophrenia in the People's Republic of China.

\section{Methods}

\section{Data search}

PubMed, Embase, and Cochrane Library databases and the Cochrane Controlled Trials Register of paliperidone ER or PP for schizophrenia in Chinese population were searched, as well as Chinese databases of China National Knowledge Infrastructure (CNKI) (http://www.cnki.net), Wanfang data (http://www.wanfangdata.com.cn) and CBM/VIP information (http://www.cqvip.com). The search included all clinical studies published between January 1, 2008, and May 22, 2015 (search date), supplemented by hand search of academic dissertations and several key literature sources. The search was conducted using several types of key terms, categories of country or region, disease classification, and treatment. For the category of country or region, the key terms were "China", "Chinese", "Taiwan", "Taiwanese", and "Hong Kong". For the category of disease classification, the search term was "schizophrenia". For the category of treatment, the key terms were "paliperidone", "9-OH risperidone", "Invega", and "Sustenna". For all the databases, search terms within each category were combined by using the Boolean operator OR. Categories were then combined by using the Boolean operator AND.

\section{Study selection}

Chinese language studies included in this review were restricted to the Chinese core medical journals, based on the Guide of Core Journal of China (2011 version) published by Peking University Press. ${ }^{6}$ The study participants were residents of the People's Republic of China, Taiwan, or Hong Kong, with a diagnosis of schizophrenia by any criteria, irrespective of age or sex. The types of intervention were paliperidone ER or PP. The included studies also had to report numerical data on at least one recognized outcome measure related to efficacy, effectiveness, or safety/tolerability. Studies were excluded if they were duplicate publications, or had no numerically reportable data on at least one relevant outcome measure. Case reports, narrative reviews, editorials, letters to the editor, or publications that did not include any formulation of paliperidone as the intervention were also excluded.

\section{Results}

\section{Results of the search}

A total of 122 publications were retrieved from the literature databases (Figure 1). Sixty of these were excluded because they did not meet the criteria of study selection. In addition, a publication about the pharmacokinetics of paliperidone ER conducted in healthy Chinese subjects, which was omitted in the initial electronic search, was added manually. A total of 63 publications were finally included in the review. Detailed information of the 63 publications are cited in Supplementary material.

\section{Characteristics of the studies}

Among the 63 publications included in the review, 53 were related to paliperidone $\mathrm{ER}$, nine were related to $\mathrm{PP}$, and one study compared paliperidone ER and PP. Most paliperidone ER-related publications were interventional studies, including 34 randomized controlled trials (RCTs) and 17 open-label, single-arm studies. Of the two nonintervention studies, one was observational, and the other a pharmacokinetic study. Of the nine PP-related studies, four were RCTs, three were observational studies, and two studies assessed the pharmacokinetics of PP in patients with schizophrenia.

These publications were published in either international peer-reviewed journals (publications in English, $n=15$ ) or Chinese core journals (publications in Chinese, $n=48$ ).

\section{Paliperidone ER}

\section{Pharmacokinetic characteristics}

Only one study had been performed to assess the pharmacokinetics of paliperidone ER in healthy Chinese subjects. ${ }^{7}$ 


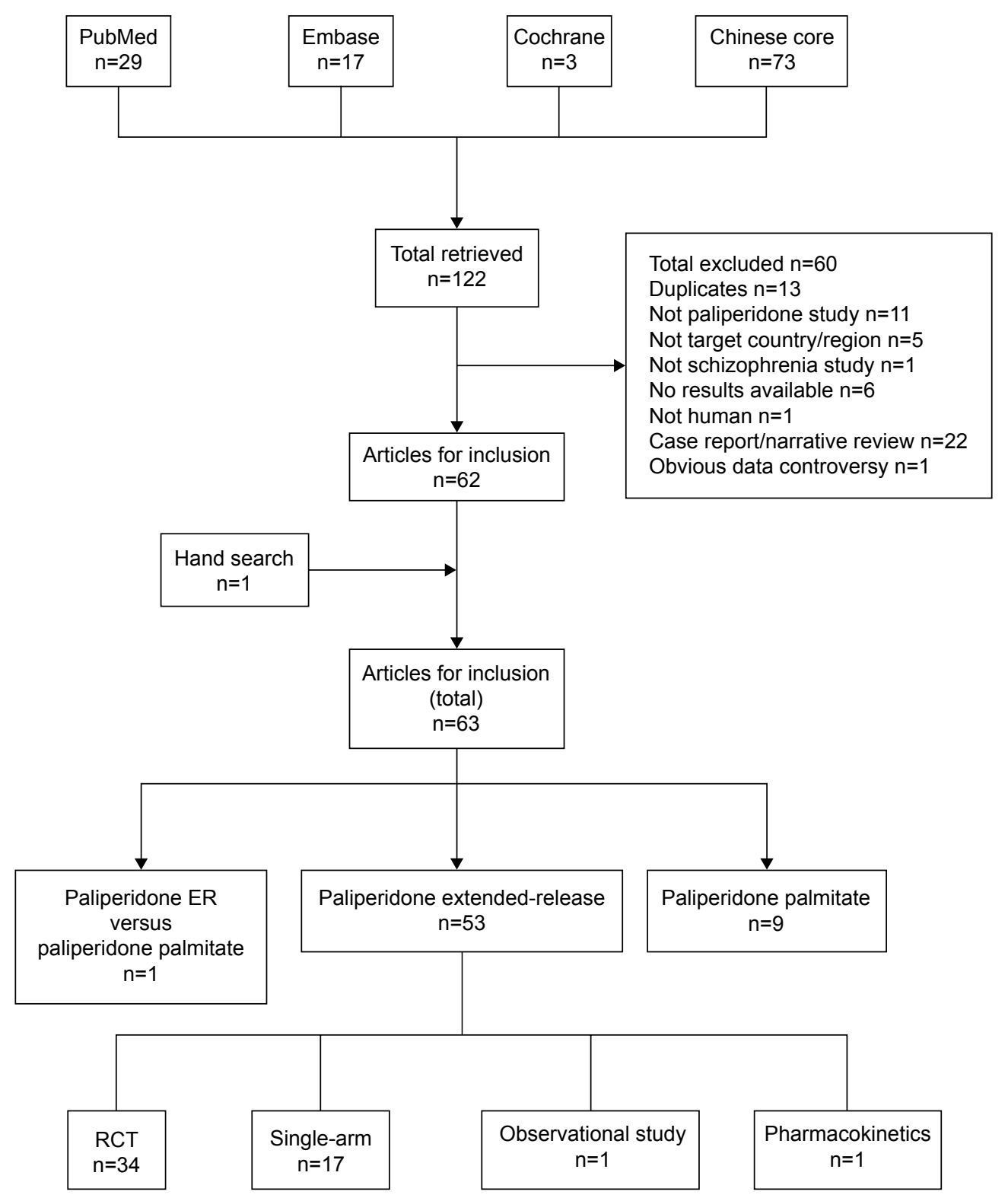

Figure I Flow diagram for study selection.

Abbreviations: ER, extended-release; RCT, randomized controlled trial.

This was a single-center, double-blind, randomized, single-dose study. A total of 24 healthy Han Chinese subjects (13 men, eleven women), aged 19-35 years, were randomly assigned in a 1:1 ratio to receive either paliperidone ER 3 or $9 \mathrm{mg}$. Mean $t_{\max }$ and $t_{1 / 2}$ were 22.2 and 22.8 hours for the $3 \mathrm{mg}$ group, and 24.8 and 21.4 hours for the $9 \mathrm{mg}$ group. Similar to the pharmacokinetic data reported for the Caucasian population, the pharmacokinetics of paliperidone ER in the Chinese population can be adequately described by a one-compartment pharmacokinetic model, and is linearly related to dose. Based on these data, paliperidone ER is suitable to be taken once daily in the morning.

\section{Efficacy outcomes}

The efficacy of paliperidone ER in Chinese patients was assessed in 35 comparative studies (Table 1) and 17 single-arm studies. All the drugs used for comparison were atypical oral antipsychotics, mostly risperidone $(\mathrm{n}=13)$ and olanzapine $(\mathrm{n}=9)$, followed by aripiprazole $(\mathrm{n}=3)$, ziprasidone $(\mathrm{n}=2)$, and clozapine $(\mathrm{n}=2)$.

The mean change in Positive and Negative Syndrome Scale (PANSS) total scores compared with baseline was the most commonly reported symptom outcome. The overall findings from comparative studies and single-arm studies were consistent: paliperidone ER treatment was associated with statistically significant reductions in PANSS total 


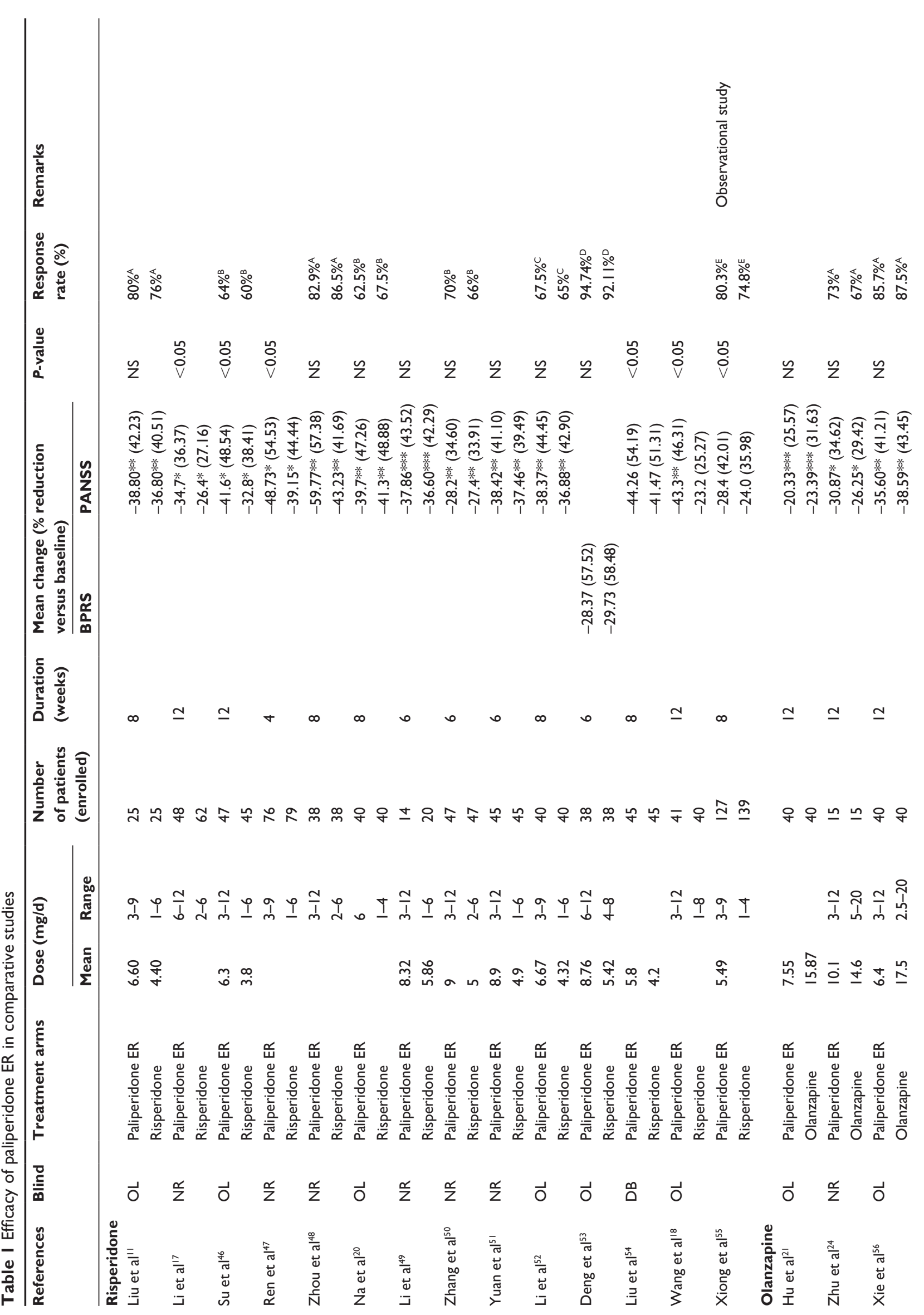




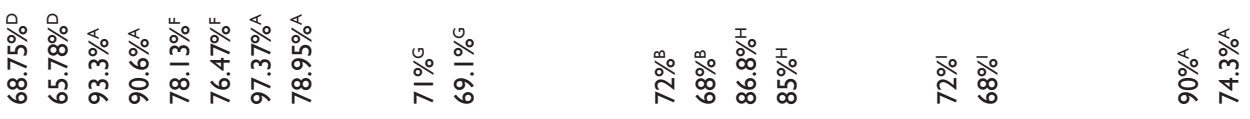

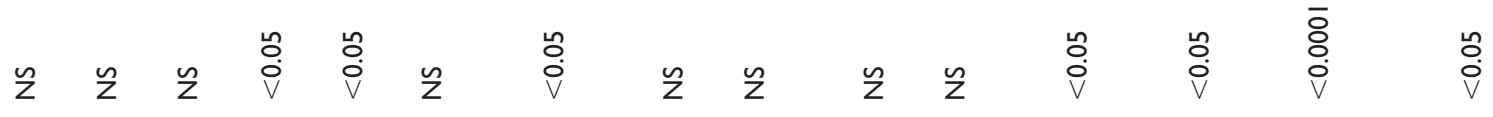

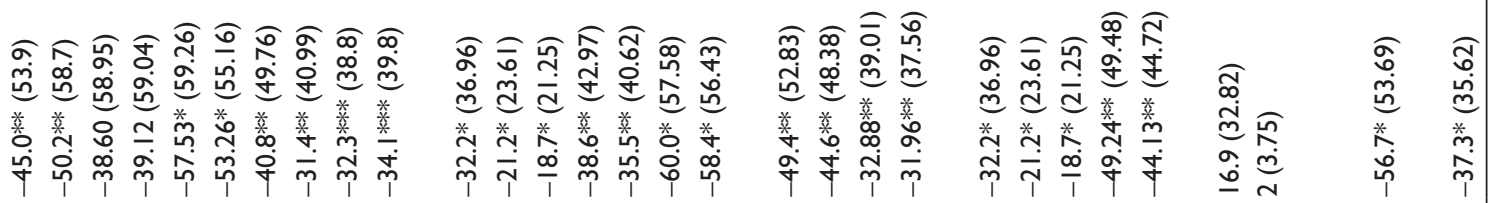

苞高

美

$\stackrel{\infty}{\uparrow} \stackrel{\infty}{\uparrow}$

$\infty \simeq \infty \quad \infty \quad \infty \quad 0 \quad$ กิ $\simeq$

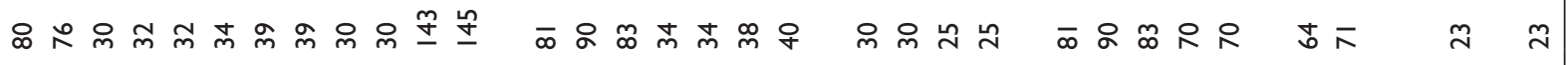

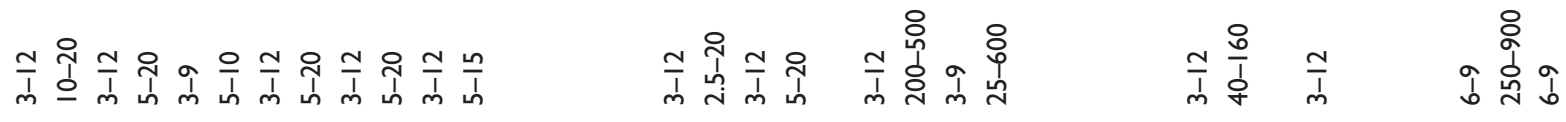

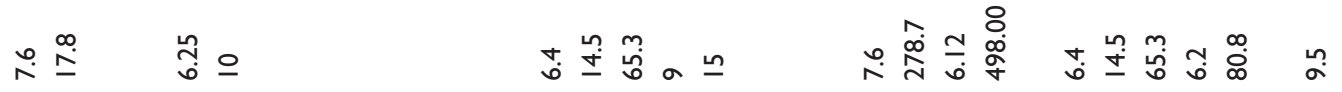

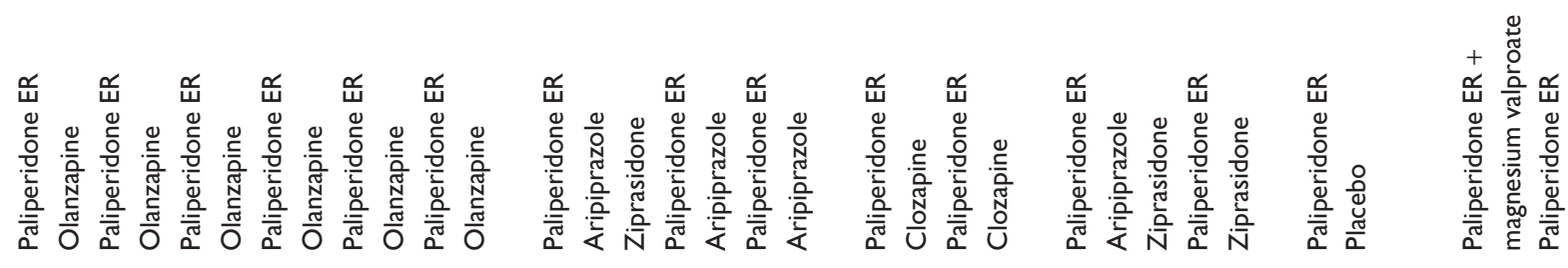

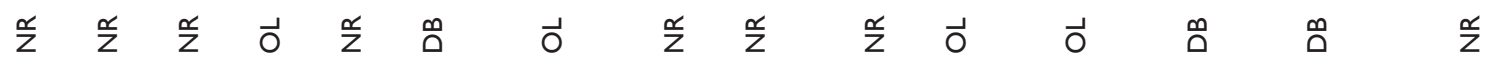

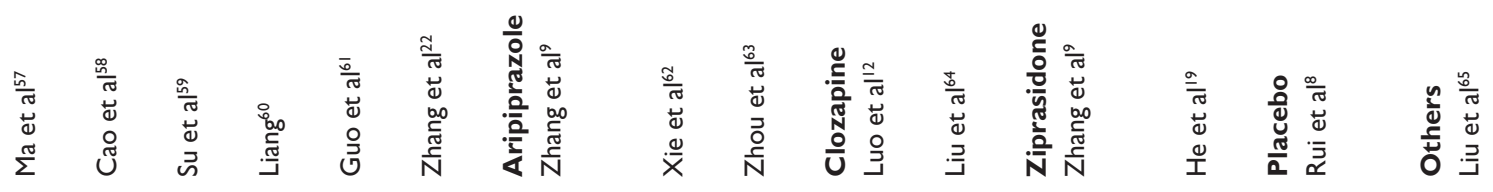




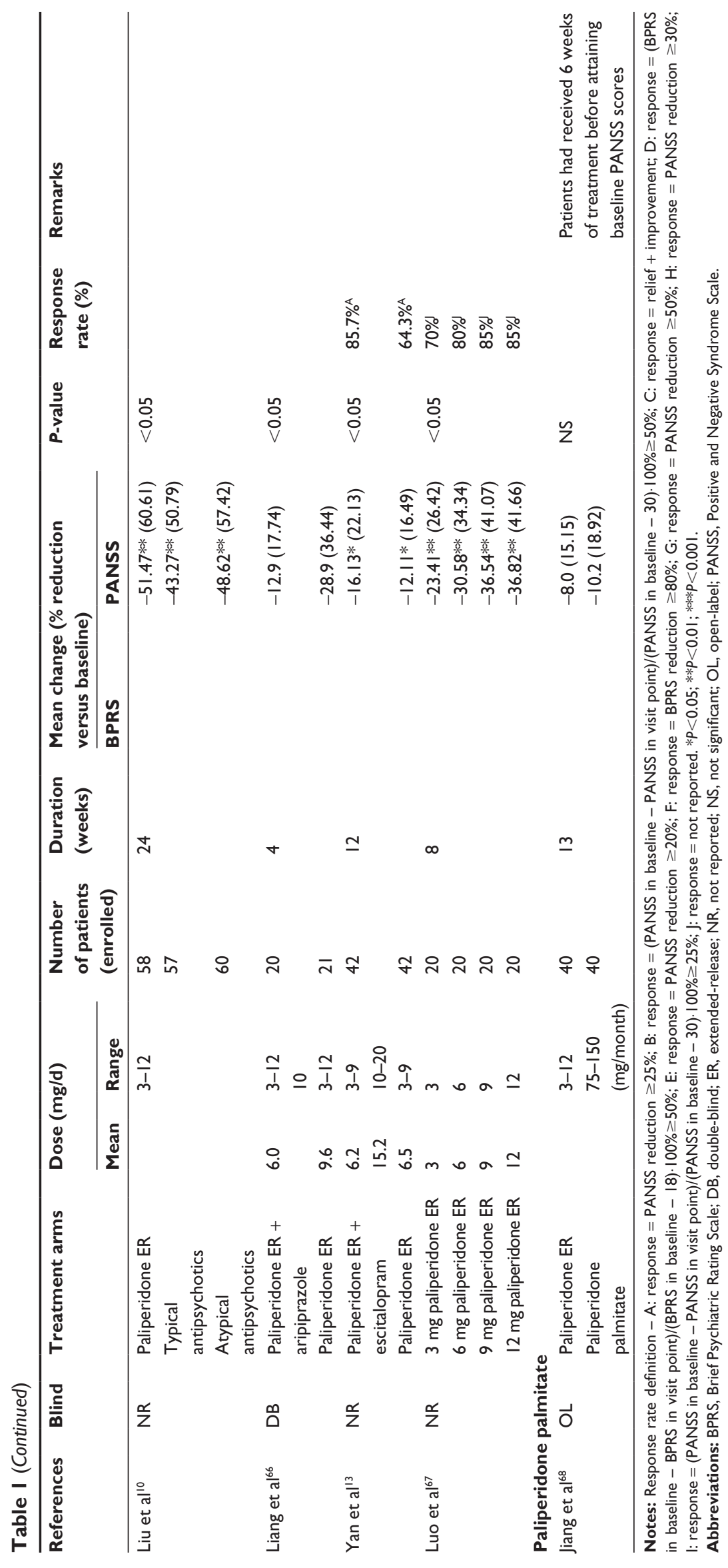


scores. The median change in PANSS total score was -38.60 in RCTs, and -34.48 in single-arm studies. In almost twothird of RCTs (21/33), the relative reduction in PANSS total score at the end point was $>40 \%$. Response rate was also a commonly used item to identify symptom outcome, but the definitions were different, and it was difficult to unify the definition of response.

Most of these studies were short-term studies, with duration of 4-12 weeks. Only three studies evaluated the longterm efficacy and safety of paliperidone ER: the duration of one study was 6 months, and that of the other two was 1 year. ${ }^{8-10}$ The results were consistent with other international data. Paliperidone ER was efficacious in the long term and significantly delayed relapse in Chinese patients with schizophrenia. No new safety signals were detected.

\section{Onset of action}

Consistent results reported that paliperidone ER has a much more rapid onset of action than risperidone or olanzapine in the first week (Table 2). Eight RCTs presented PANSS or Brief Psychiatric Rating Scale (BPRS) total score data in week 1; three of these compared the data for paliperidone ER with that for risperidone, and five compared the data for paliperidone ER with that for olanzapine. In all these eight studies, paliperidone ER effected significant reduction in PANSS total score at week 1 compared with that at baseline. The paliperidone ER group achieved lower PANSS or BPRS total score at week 1 in all studies compared with risperidone $(3 / 3, P<0.05)$, and in most studies compared with olanzapine $(3 / 5, P<0.05)$. Paliperidone ER treatment also resulted in significantly lower PANSS or BPRS total scores compared with risperidone in week 2; however, the results were comparable with those for olanzapine. There was not enough information to determine the dose details in week 1 and week 2 , but the $\mathrm{OROS}^{\circledR}$ technology of paliperidone ER allowed initiation with effective dosage, which could benefit the onset.

\section{Effectiveness outcomes}

Seventeen comparative studies and 12 single-arm studies reported effectiveness outcomes, including functionality, neurocognitive function, and quality of life. The most commonly used effectiveness assessment was the Personal and Social Performance Scale (PSP) to assess functionality. Eleven comparative studies and ten single-arm studies reported PSP outcome. Paliperidone ER treatment significantly improved the PSP score at the end point compared with that at baseline in all these studies (Table 3). In all eleven comparative studies, paliperidone ER resulted in significantly better PSP scores at the end point than those achieved with comparative drugs, including risperidone, olanzapine, and aripiprazole.

Three comparative studies and three single-arm studies reported neurocognitive function outcome, ${ }^{11-16}$ assessed by different tools including the Wisconsin Card Sorting Test, Wechsler Memory Scale-Revised, Stroop, or Measurement and Treatment Research to Improve Cognition in Schizophrenia initiative - Consensus Cognitive Battery. Neurocognitive outcome was the primary outcome in one comparative study and three single-arm studies. In all these studies, paliperidone ER treatment significantly improved neurocognitive function at the end point compared with that at baseline.

Quality of life was assessed in four trials, ${ }^{12,17-19}$ using different tools including the Short Form-36 Health Survey, The World Health Organization Quality of Life 100, Social Disability Screening Schedule, and Overall Quality of Life Rating Scale. In all these studies, paliperidone ER treatment significantly improved the quality of life at the end point compared with that at baseline.

\section{Safety and tolerability}

Safety and tolerability outcome was reported in most studies. The most commonly reported treatment-emergent adverse events (TEAEs) were extrapyramidal symptoms (EPSs), insomnia or somnolence, and prolactin-related TEAEs. Paliperidone ER was generally well tolerated in the Chinese population, and no special safety signal was found.

\section{Extrapyramidal symptoms}

EPSs were the most frequently reported TEAE reported in these articles as EPS, akathisia, dyskinesia, tumor, dystonia, and Parkinsonism. The incidence of EPSs associated with paliperidone ER treatment was lower than that with risperidone treatment but higher than that with olanzapine treatment.

\section{Prolactin elevation}

Six RCTs and three single-arm studies tested plasma prolactin level; the study duration ranged from 4 to 12 weeks. Paliperidone ER significantly increased plasma prolactin level compared with that at baseline. The prolactin level in the paliperidone ER group was significantly lower than that in the risperidone group but higher than that in the olanzapine and aripiprazole groups. The potential prolactinrelated TEAEs were not especially reported in most studies. In five studies that reported potential prolactin-related TEAEs, including irregular menstruation, amenorrhea, galactorrhea, and gynecomastia, the total incidence was $0 \%-5 \% .{ }^{17,20-23}$ 


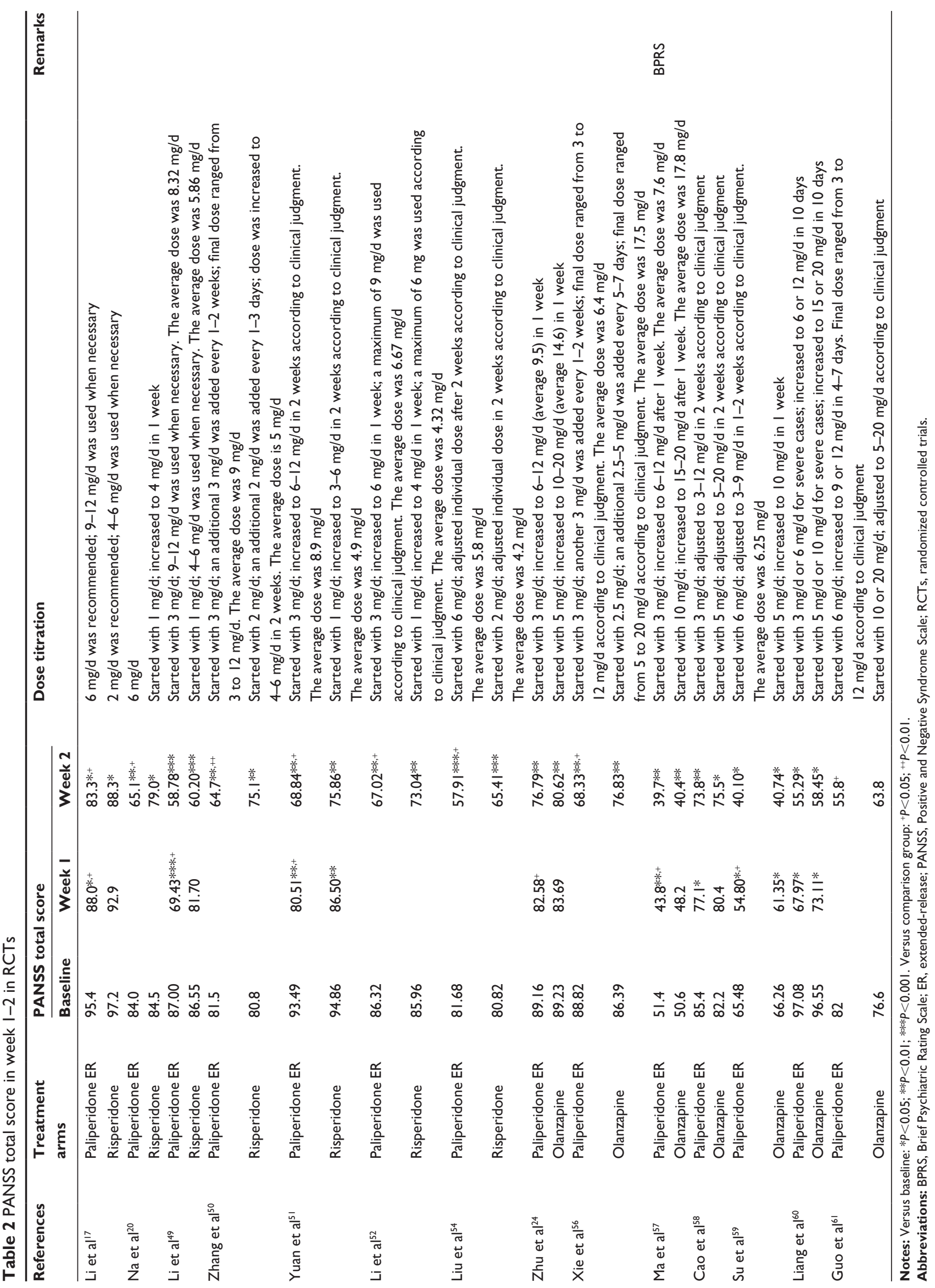




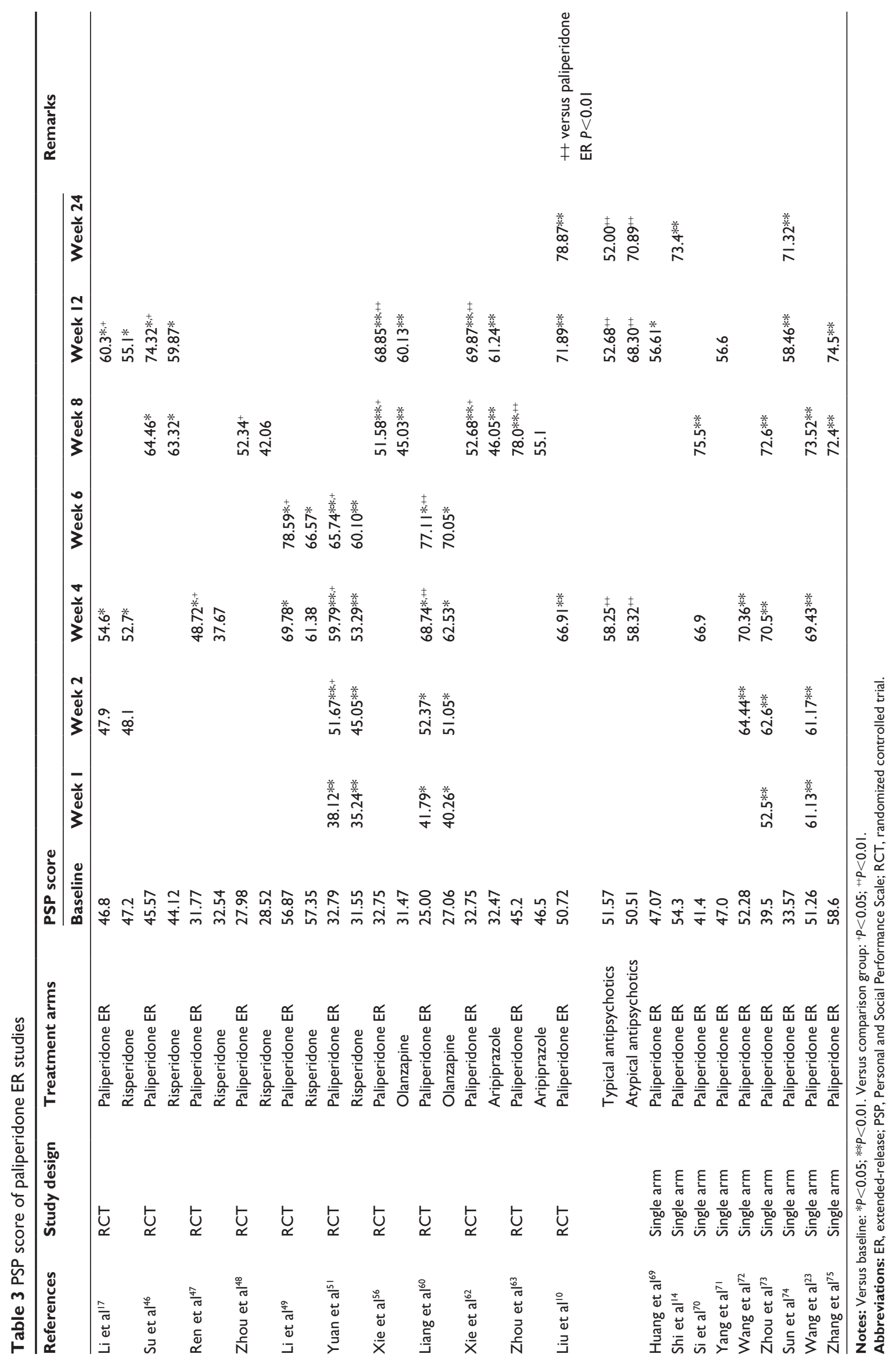




\section{Weight and metabolic parameters}

Eight RCTs and four single-arm studies reported outcomes related to weight gain and metabolic parameters. Most of the studies had a duration of 6-12 weeks, except a 52-week study. The most commonly assessed metabolic parameters were levels of glucose and lipids in plasma. In the 6- to 12-week studies, paliperidone ER treatment resulted in an insignificant change or significant but mild change in mean weight. Paliperidone ER treatment caused no significant change in blood glucose levels. In most studies, paliperidone ER treatment caused no significant change in lipid metabolism, although some studies showed a small increase in triglyceride levels. Generally, in these short-duration studies, paliperidone ER was well tolerated in terms of effect on weight and metabolic parameters, and had some advantage over olanzapine in terms of weight gain, and glucose and lipid metabolism. ${ }^{21,22,24}$

\section{Paliperidone palmitate}

PP-related studies in the Chinese population included two pharmacokinetic studies, four comparative studies, and three single-arm studies.

Among the pharmacokinetic studies, the first one was an open-label, randomized, parallel-group, multicenter study in patients with chronic schizophrenia. ${ }^{25}$ On day 1, 48 eligible subjects were randomly assigned in a 1:1:1 ratio to 25,100 , or $150 \mathrm{mg}$ PP groups; the same dose as that assigned on day 1 was injected on day 8 on the other side of the gluteal muscle. The plasma concentrations of paliperidone gradually increased to a $C_{\max }$ at a mean $t_{\max }$ of 13 days. The area under the curve (AUC) (0-35 days), AUC (0-210 days), and AUC $(0-\infty)$ for the three doses were dose-proportional. The median half-life $\left(t_{1 / 2}\right)$ ranged from 42 to 77 days, and the $t_{1 / 2}$ was prolonged for higher doses. The therapeutic regimen for PP in this study was different from the recommended regimen. The second study was designed to evaluate the pharmacokinetics of PP after multiple doses (the recommended dosing regimen): $150 \mathrm{mg}$ on day 1 , followed by $100 \mathrm{mg}$ on day $8 .{ }^{26}$ Thereafter, a flexible dose $(75,100$, or $150 \mathrm{mg})$ was administered monthly, based on the patient's response, consecutively for 6 months. The mean $C_{\max }$ was $17-25 \mathrm{ng} / \mathrm{mL}$ at a mean $t_{\max }$ of 11-17 days. Based on these data, the pharmacokinetic characteristics of PP in the Chinese population were similar to those found in studies on the Caucasian population. ${ }^{27,28}$

The first comparative study was a registration study of PP for its introduction to the Chinese market. ${ }^{29}$ It was a noninferiority-design, open-label, rater-blinded, parallelgroup, 13-week study. The active comparator was risperidone long-acting injectable (RIS-LAI, 25-50 mg/2 weeks). A significant improvement with respect to baseline was observed at the end point for both groups; mean (standard deviation) change from baseline to end point in PANSS total scores was -23.6 (16.28) for the PP group and -26.9 (15.43) for the RIS-LAI group. The mean change in PSP was 16.8 (PP group) and 18.6 (RIS-LAI group), and the overall incidence of TEAEs was not different between the groups.

Three subsequent small sample size, open-label, randomized, comparative studies of PP and oral risperidone were conducted with the recommended initiation dosing regimen for PP over durations of 6, 8, and 12 weeks. ${ }^{30-32}$ The mean change from baseline to end point in PANSS total score and the tolerability were comparable between both groups. A total of three single-arm studies of PP was conducted to establish the effects of PP on acute or recent-onset patient hospitalization rates. ${ }^{33-35}$ The results showed that PP treatment significantly $(P<0.0001)$ reduced both the number of hospitalizations and the number of days spent in the hospital. The most frequently reported TEAEs were injection-site pain, EPSs, akathisia, and insomnia.

\section{Discussion}

This study was a systematic review carried out to critically evaluate the efficacy, effectiveness, and safety of paliperidone (as the oral ER and 1-month long-acting injection formulations) in the Chinese population. The results demonstrated that the efficacy of paliperidone ER was at least comparable with that of other atypical antipsychotics, which was consistent with the results of the latest meta-analysis of Chinese patients with schizophrenia. ${ }^{36}$ The onset of symptom control was faster in the paliperidone ER group, compared with the risperidone group at week 1 and week 2 , and the olanzapine treatment at week 1 . This may be because the OROS $^{\circledR}$ technology and pharmacokinetic profile of paliperidone ER allow once-daily dosing with an initial dose of $6 \mathrm{mg}$ and no need for initial dose titration, which enables rapid action. A review summarized the time required to achieve significant alleviation of psychiatric symptoms compared with baseline, ${ }^{37}$ paliperidone ER and risperidone showed alleviation of symptoms from day 4, while olanzapine, aripiprazole, and ziprasidone took 1-2 weeks. However, there were no available head-to-head comparison results. Our findings could help to enrich the data on antipsychotic onset of action. Paliperidone was well tolerated in the Chinese population, and no special safety issues were found. The incidence of EPSs and increase in prolactin levels associated with paliperidone ER treatment were lower than that with risperidone treatment but higher than that with olanzapine treatment. This was consistent with the result of other studies.

Paliperidone ER treatment resulted in a significantly better PSP score at the end point compared with other antipsychotics 
including risperidone, olanzapine, and aripiprazole. This was a novel finding of our systematic review. There are a limited number of randomized controlled studies comparing paliperidone ER and other antipsychotics in international publications. No RCTs have compared the functionality outcome between paliperidone ER and risperidone or aripiprazole. Three 6-week studies identified the efficacy and safety of paliperidone ER, and used olanzapine $10 \mathrm{mg} / \mathrm{d}$ treatment to confirm trial validity; the pooled data showed that there was no significant difference in mean PSP score change from baseline to end point between paliperidone ER and olanzapine groups. A period of 6 weeks may not be enough to test the functionality outcome, as it is influenced by several factors, including not only positive symptoms but also negative symptoms, affective symptoms, cognitive symptoms, and side effects such as sedation and metabolic syndrome. ${ }^{38-42}$ The efficacy of paliperidone ER is at least comparable to that of other antipsychotics, and it has a better safety profile than risperidone, and less severe sedative and metabolic effects than olanzapine. This might be the reason for the better functionality outcome of paliperidone ER treatment found in our review. However, the sample size of studies included in this systematic review is relatively small, and PSP is not the primary end point in most studies, so the effectiveness of antipsychotics in functionality improvement still needs further verification in the future. Results from studies on PP demonstrated that it is an effective and welltolerated treatment for Chinese patients with schizophrenia, and may have some advantage in terms of functionality and patient's medication satisfaction compared with the oral formulation. Additionally, several studies have demonstrated that LAI has an advantage over oral antipsychotics in preventing relapse, and in reducing hospitalization rate and number of hospitalization days..$^{34,43,44}$ The studies on PP were fewer than those on paliperidone ER; a People's Republic of China international survey in 2012 showed that only $2.75 \%$ of patients with schizophrenia use LAI antipsychotics, and only $0.48 \%$ use atypical LAIs. ${ }^{45}$ Both LAI data on clinical research and LAI usage in clinical practice need to be improved in the People's Republic of China.

There were some problems related to study quality, especially with publications from Chinese core journals. Most of the RCTs from Chinese core journals in this review did not clearly elucidate the methods of randomization, or information about blinding. Some studies did not give detailed information about mean dose, which caused difficulty in comparing between different treatment arms. The duration of most studies was 6-12 weeks; long-term studies were relatively fewer. Additionally, the sample sizes of some studies were relatively small.

\section{Conclusion}

Paliperidone is one of the first-line antipsychotics used in the People's Republic of China. Both paliperidone ER and PP are effective, safe, and well tolerated in Chinese patients with schizophrenia according to the data we reviewed. Paliperidone may have some advantage over other antipsychotics in terms of onset of action and functionality improvement. Future studies could focus more on long-term data and LAI treatment.

\section{Acknowledgment}

This work was supported by the National Key Technology R\&D Program (2015BAI13B01). The funding body had no role in the study design, data collection and analysis, decision to publish, or preparation of the manuscript.

\section{Author contributions}

All authors contributed toward data analysis, drafting and revising the paper, and agree to be accountable for all aspects of the work.

\section{Disclosure}

LiLi Zhang is an employee of Xian Janssen Medical Affairs. YanJie Zhao is an intern at Xian Janssen Medical Affairs. Xian Janssen did not provide any financial support for this work. The authors report no other conflicts of interest in this work.

\section{References}

1. Phillips MR, Zhang J, Shi Q, et al. Prevalence, treatment, and associated disability of mental disorders in four provinces in China during 2001-2005: an epidemiological survey. Lancet. 2009;373(9680):2041-2053.

2. Mannens G, Huang M, Meuldermans W, Hendrickx J, Woestenborghs R, Heykants J. Absorption, metabolism, and excretion of risperidone in humans. Drug Metabolism and Disposition. 1993;21(6):1134-1141.

3. Schotte A, Janssen P, Gommeren W, et al. Risperidone compared with new and reference antipsychotic drugs: in vitro and in vivo receptor binding. Psychopharmacology. 1996;124(1-2):57-73.

4. Conley R, Gupta S, Sathyan G. Clinical spectrum of the osmotic-controlled release oral delivery system (OROS), an advanced oral delivery form. Current Medical Research and Opinion. 2006;22(10):1879-1892.

5. Gopal S, Gassmann-Mayer C, Palumbo J, Samtani M, Shiwach R, Alphs L. Practical guidance for dosing and switching paliperidone palmitate treatment in patients with schizophrenia. Current Medical Research and Opinion. 2010;2(26):377-387.

6. Guide of Core Journals of China (2011 version). 6th edition. Beijing: Peking University Press, 2011.

7. Si T, Shu L, Liu Y, Su Y. Single-dose pharmacokinetics of paliperidone extended-release tablets in healthy Chinese subjects. Human Psychopharmacology: Clinical and Experimental. 2010;25(5):404-409.

8. Rui Q, Wang Y, Liang S, et al. Relapse prevention study of paliperidone extended-release tablets in Chinese patients with schizophrenia. Progress in Neuro-Psychopharmacology and Biological Psychiatry. 2014; 53(2014):45-53.

9. Zhang Y, Dai G. Efficacy and metabolic influence of paliperidone ER, aripiprazole and ziprasidone to patients with first-episode schizophrenia through 52 weeks follow-up in China. Human Psychopharmacology: Clinical and Experimental. 2012;27(6):605-614. 
10. Liu Z, Zheng Y, Zheng T, An L. Efficacy of paliperidone extendedrelease tablets on improving social function in acute patients with schizophrenia. Journal of Shandong University (Health Science). 2011; 49(8):100-103.

11. Liu M, Liu X, Miao X, Gao X. Effects of paliperidone extended-release tablets and risperidone on cognitive function in patients with firstepisode schizophrenia. Chinese Journal of New Drugs. 2012;21(4): 419-422.

12. Luo S, Sun Q, Zeng D. The effects of paliperidone extended-release and clozapine on the life quality of schizophrenia patients. Journal of Practical Medicine. 2012;28(6):986-988.

13. Yan D, Zhou L, Ma X, Deng X, Zhang X. The effects of paliperidone combined with Escitalopram on the cognitive functions and negative symptoms of schizophrenia patients. Chinese Journal of Prevention and Control of Chronic Diseases. 2014;22(4):481-483.

14. Shi C, Yu X, Kang L, et al. Paliperidone ER treatment and the improvement of social and cognitive function in patients with schizophrenics - a 24-week, single arm, open-label study. Schizophrenia Research. 2014;153(Suppl 1):S118.

15. Chen F, Zhou H, Lu Z, et al. Cognitive effect of flexible-dose oral paliperidone extended-release tablets in treating acute schizophrenia. Chinese Journal of New Drugs. 2012;21(19):2297-2301.

16. Zhang Y, Lei J, Hu Y. Effects of paliperidone on executive functions of schizophrenia patients. Modern Preventive Medicine. 2013;40(18): $3448-3450$

17. Li C, Yang G, Chen H, et al. Efficacy, tolerability, quality of life and social functioning in schizophrenia patients after treatment with oral paliperidone extended-release tablets. Chinese Journal of New Drugs. 2012;21(12):1372-1376.

18. Wang Y, Li W, Gu D, et al. Efficacy of paliperidone extended-release tablets in the improvement of social functions in schizophrenics: a randomized and controlled study. National Medical Journal of China. 2010;90(29):2030-2035.

19. He J, Tao Y, Long S, Zhou J. Influence of paliperidone extended-release tablets on the social function and quality of life in patients with schizophrenia. Journal of Chinese Pharmacy. 2012;47(13):1090-1093.

20. Na W, Su W, Li J, et al. Comparison of paliperidone ER and risperidone in the treatment of schizophrenia. Chinese Journal of New Drugs. 2011;20(8):708-720.

21. Hu S, Yao M, Peterson BS, et al. A randomized, 12-week study of the effects of extended-release paliperidone (paliperidone ER) and olanzapine on metabolic profile, weight, insulin resistance, and $\beta$-cell function in schizophrenic patients. Psychopharmacology. 2013;230(1): $3-13$.

22. Zhang H, Li H, Wang G, et al. The efficacy and safety of flexible doses of paliperidone extended-release tablets in the treatment of acute schizophrenia: a randomized, double blind olanzapine-controlled study. Chinese Journal of Psychiatry. 2009;42(3):153-157.

23. Wang Z, Wang G, Wang H, Wang X. Clinical efficacy of paliperidone controlled release tablets and its influence on serum prolactin level in patients with acute schizophrenia. Chinese Journal of New Drugs. 2009; 18(21):2052-2055.

24. Zhu Q, Pi J. A comparative study of paliperidone and olanzapine in the treatment of treatment-refractory schizophrenia. Chinese Journal of New Drugs. 2012;21(6):666-669.

25. Si T, Su Y, Liu Y, et al. Pharmacokinetics and tolerability of paliperidone palmitate injection in Chinese subjects. Human Psychopharmacology: Clinical and Experimental. 2014;29(2):203-210.

26. Li D, Mi W, Li L, Wang Z, Wang Y, Zhang H. Plasma concentrations of intramuscular paliperidone palmitate and the relationship between the dose and clinical safety. Chinese Journal of Clinical Pharmacology. 2012;28(8):563-565.

27. Cleton A, Rossenu S, Crauwels H, et al. A single-dose, open-label, parallel, randomized, dose-proportionality study of paliperidone after intramuscular injections of paliperidone palmitate in the deltoid or gluteal muscle in patients with schizophrenia. Journal of Clinical Pharmacology. 2014;54(9):1048-1057.
28. Hough D, Lindenmayer J, Gopal S, et al. Safety and tolerability of deltoid and gluteal injections of paliperidone palmitate in schizophrenia. Progress in Neuro-psychopharmacology and Biological Psychiatry. 2009;33(6):1022-1033.

29. Li H, Rui Q, Ning X, Xu H, Gu N. A comparative study of paliperidone palmitate and risperidone long-acting injectable therapy in schizophrenia. Progress in Neuro-Psychopharmacology and Biological Psychiatry. 2011;35(4):1002-1008.

30. Wakamatsu A, Takahashi N, Takahashi M, et al. Efficacy and safety of paliperidone palmitate in Asian patients with schizophrenia: a 13-week double-blind study. European Neuropsychopharmacology. 2013; 23(Suppl 2):S466.

31. Ma J, Li Y, Xu H, et al. Efficacy and safety of paliperidone palmitate injection in the treatment of schizophrenia in teenagers. Chinese Journal of New Drugs. 2014;23(8):972-976.

32. Yi F, Liu X, Zhen L. Efficacy and safety of paliperidone palmitate injection in treatment of acute schizophrenia. Chinese Journal of New Drugs and Clinical Remedies. 2013;32(12):988-992.

33. Bressington D, Stock J, Hulbert S, MacInnes D. A retrospective observational study of the effectiveness of paliperidone palmitate on acute inpatient hospitalization rates. International Clinical Psychopharmacology. 2015;30(4):230-236.

34. Zhang F, Si T, Chiou C, et al. Efficacy, safety, and impact on hospitalizations of paliperidone palmitate in recent-onset schizophrenia. Neuropsychiatric Disease and Treatment. 2015;11:657-668.

35. Miao X, Wang Q, Liu L, Bai L. An open-label study on the efficacy of paliperidone palmitate in patients with acute schizophrenia. Chinese Journal of New Drugs. 2014;23(19):2280-2283.

36. Cai S, Lu H, Bai Z, Wu R, Zhao J. Paliperidone extended-release tablets in Chinese patients with schizophrenia: meta-analysis of randomized controlled trials. Neuropsychiatric Disease and Treatment. 2015;11:1817-1834.

37. Gardner K, Bostwick J. Antipsychotic treatment response in schizophrenia. American Journal of Health-System Pharmacy. 2012;69(21): $1872-1879$

38. Gorna K, Jaracz K, Wrzyszczynska L, Rybakowski F. Quality of life and depression in schizophrenic patients. Advances in Medical Science. 2007;52(Suppl 1):108-111.

39. González-Blanch C, Perez-Iglesias R, Pardo-García G, et al. Prognostic value of cognitive functioning for global functional recovery in first-episode schizophrenia. Psychological Medicine. 2010;40(6):935-944.

40. Green M, Kern R, Braff D, Mintz J. Neurocognitive deficits and functional outcome in schizophrenia: are we measuring the "right stuff"? Schizophrenia Bulletin. 2000;26(1):119-136.

41. Stahl SM, Mignon L, Munter N. Side effects of antipsychotics: metabolic issues and sedation. In: Stahl SM, Mignon L, editors. Stahl's Illustrated Antipsychotics: Treating Psychosis, Mania and Depression. Cambridge: Cambridge University Press, 2010.

42. Kolotkin R, Corey-Lisle P, Crosby R, et al. Impact of obesity on healthrelated quality of life in schizophrenia and bipolar disorder. Obesity (Silver Spring). 2008;16(4):749-754.

43. Schreiner A. prevention of relapse with oral antipsychotics versus injectable paliperidone palmitate. Poster presented at: the 29th CINP (The International College of Neuropsychopharmacology) in Vancouver, Canada; June 22-26; 2014.

44. Kishimoto T, Nitta M, Borenstein M, Kane J, Correll C. Long-acting injectable versus oral antipsychotics in schizophrenia: a systematic review and meta-analysis of mirror-image studies. The Journal of Clinical Psychiatry. 2013;74(10):957-965.

45. Si TM. The third survey of prescription pattern of psychotropic drugs in China: schizophrenia patients prescription status. Presented at: The Chinese Society of Neuroscience \& Psychiatry Annual Meeting; June 26-28; 2014; Nan Chang, China.

46. Su W, Li J, Yang J, Guan T, Na W. Effects of paliperidone on social functioning in schizophrenia patients; a randomized, opened, controlled trial. Chinese Journal of New Drugs and Clinical Remedies. 2012;31(6): 345-349. 
47. Ren H, Li L. Clinical study on the efficacy of paliperidone extendedrelease tablets in the treatment of schizophrenia outpatients and its effect on social function. Chinese Journal of New Drugs. 2012;21(14): 1636-1638.

48. Zhou H, Wang S. Clinical efficacy of paliperidone in treatment of first episode schizophrenia. The Journal of Practical Medicine. 2012;28(23): 3986-3988.

49. Li X, Pan L, Jin G, Han X. The efficacy and safety of paliperidone-extended release capsules on treating adolescent schizophrenia Shandong Medical Journal. 2011;51(15):96-97.

50. Zhang H, Liang W, Guo S. Comparison of efficacy and safety between paliperidone and risperidone in patients with schizophrenia. Chinese Journal of New Drugs and Clinical Remedies. 2011;30(7):517-521.

51. Yuan T, Qin L, Yao M, Tang J, Yue W. Effects of paliperidone extendedrelease tablets on the personal and social functions in acute patients with schizophrenia. The Chinese Journal of Clinical Pharmacology. 2011;27(9):672-675.

52. Li L, Li J, Yang J, Dai X, Su W, Yu B. A comparative study of the effects of paliperidone and risperidone on the glucose and lipid metabolism in first-episode male schizophrenia patients. Chinese Pharmaceutical Journal. 2013;48(8):649-651.

53. Deng X, Yang Y, Wang Q, Yin L. The comparison study on efficacy and safety of paliperidone extended-release and risperidone on female, first-episode schizophrenia patients. Chinese Journal of Nervous and Mental Disease. 2013;39(6):355-358.

54. Liu J, Yang J, Yang S, Chen Z. The efficacy and safety of paliperidone extended-release tablets for first-episode schizophrenia. The Journal of Practical Medicine. 2010;26(20):3775-3777.

55. Xiong D, Wang Q, Tu J, Wang Y. Clinical observation on paliperidone sustained release tablet in the treatment of schizophrenia in outpatient. China Pharmacy. 2010;21(18):1681-1682.

56. Xie Q, Feng S, Zeng H, Xu Y, Wang J. Efficacies of paliperidone extended-release tablets and olanzapine for treating schizophrenia in children and adolescents. Chinese Journal of New Drugs. 2012;21(16): 1916-1919.

57. Ma Q, Li L, Lian H. A controlled comparison study on paliperidone extended-release tablets and olanzapine in the treatment of schizophrenia. Chinese Journal of New Drugs. 2012;21(22):2658-2661.

58. Cao G, Xie G. Observation of efficacy and safety of paliperidone sustained release tablets and domestic olanzapine in treatment of schizophrenia. Chongqing Medicine. 2011;40(17):1695-1696.

59. Su H, Fu W, Li D, Li Q, Chen J. Comparative study for treatment with Paliperidone release tablets and Olanzapine in schizophrenia. Chongqing Medicine. 2011;40(27):2751-2753.

60. Liang Y. A clinical comparative study on paliperidone ER in treating acute phase schizophrenia patients. Chinese Journal of New Drugs. 2011; 20(24):2442-2445.

61. Guo X, Wang G, Wang Z, Wang N. The effects of paliperidone extended-release tablets and olanzapine on the liver function of patients with schizophrenia. Chinese Journal of New Drugs. 2014;23(16): 1941-1945.
62. Xie Q, Tang J, Zhou L, Zeng H. A controlled clinical study between paliperidone and aripiprazole in adolescents first-episode schizophrenia. Chinese Journal of New Drugs and Clinical Remedies. 2013; 32(1):51-55.

63. Zhou H, Wang S, Li Y, et al. Therapeutic efficacy of paliperidone in the treatment of male patients with schizophrenia and its effects on sexual function. Chinese Journal of Hospital Pharmacy. 2013;33(4):308-311.

64. Liu M, Liu X, Zhang N. A comparative study on efficacy and safety of paliperidone extended-release tablets and clozapine in treatment of resistant schizophrenia. Chinese Journal of New Drugs. 2012;21(14): 1639-1642.

65. Liu Z, Sun Y, Wang L. The efficacy of Magnesium Valproate combined with paliperidone on treating 23 schizophrenia patients. Shandong Medical Journal. 2011;51(23):54-55.

66. Liang J, Yan J, Zhang X. Aripirazole reduces paliperidone-induced increase of prolactin in patients with schizophrenia: a randomized, double blind and placebo-controlled study. Chinese Journal of New Drugs. 2014;23(11):1300-1310.

67. Luo R, Chen R. Clinical efficacy and safety of paliperidone extendedrelease tablets in different dosage groups in the treatment of schizophrenia. Chinese Journal of New Drugs. 2012;21(18):2193-2195.

68. Jiang J, Li X, Tang C, Zhang J. The efficacy and safety of paliperidone palmitate versus paliperidone extended-release on patients with schizophrenia. Guangdong Medical Journal. 2014;35(9):1414-1416.

69. Huang M, Yang T, Ten P, Liu I, Chiu W, Li C. Effects of paliperidone extended release on the symptoms and functioning of schizophrenia. BMC Clinical Pharmacology. 2012;12:1.

70. Si T, Tan Q, Zhang K, Wang Y, Rui Q. An open-label, flexible-dose study of paliperidone extended-release in Chinese patients with firstonset psychosis. Neuropsychiatric Disease and Treatment. 2015;11: 87-95.

71. Yang T, Huang M. Correlation between PANSS and personal and social performance (PSP) improvements in patients with schizophrenia by paliperidone ER treatment. International Journal of Neuropsychopharmacology. 2010;13(Suppl 1):112.

72. Wang H, Wang G, Wang H, Shu C, Bai X, Shu Y. Clinical efficacy and patient satisfaction evaluation in acute schizophrenia with paliperidone extended release therapy. Medical Journal of Wuhan University. 2012;33(2):259-262.

73. Zhou H, Chen F, Lu Z, et al. Efficacy and safety of flexible-dose oral paliperidone extended-release tablets in the treatment of acute schizophrenia. Chinese Journal of New Drugs. 2012;21(12):1367-1371.

74. Sun L, Zhou T, Lei T. Efficacy and safety of paliperidone ER in the treatment of adolescent patients with first-episode schizophrenia. Chinese Journal of New Drugs. 2011;20(9):799-802.

75. Zhang H, Hao X, Wang X, et al. An open-label study on the safety and efficacy of paliperidone extended-release in non-acute schizophrenic patients. Chinese Journal of Psychiatry. 2012;45(1):20-24. 


\section{Supplementary material}

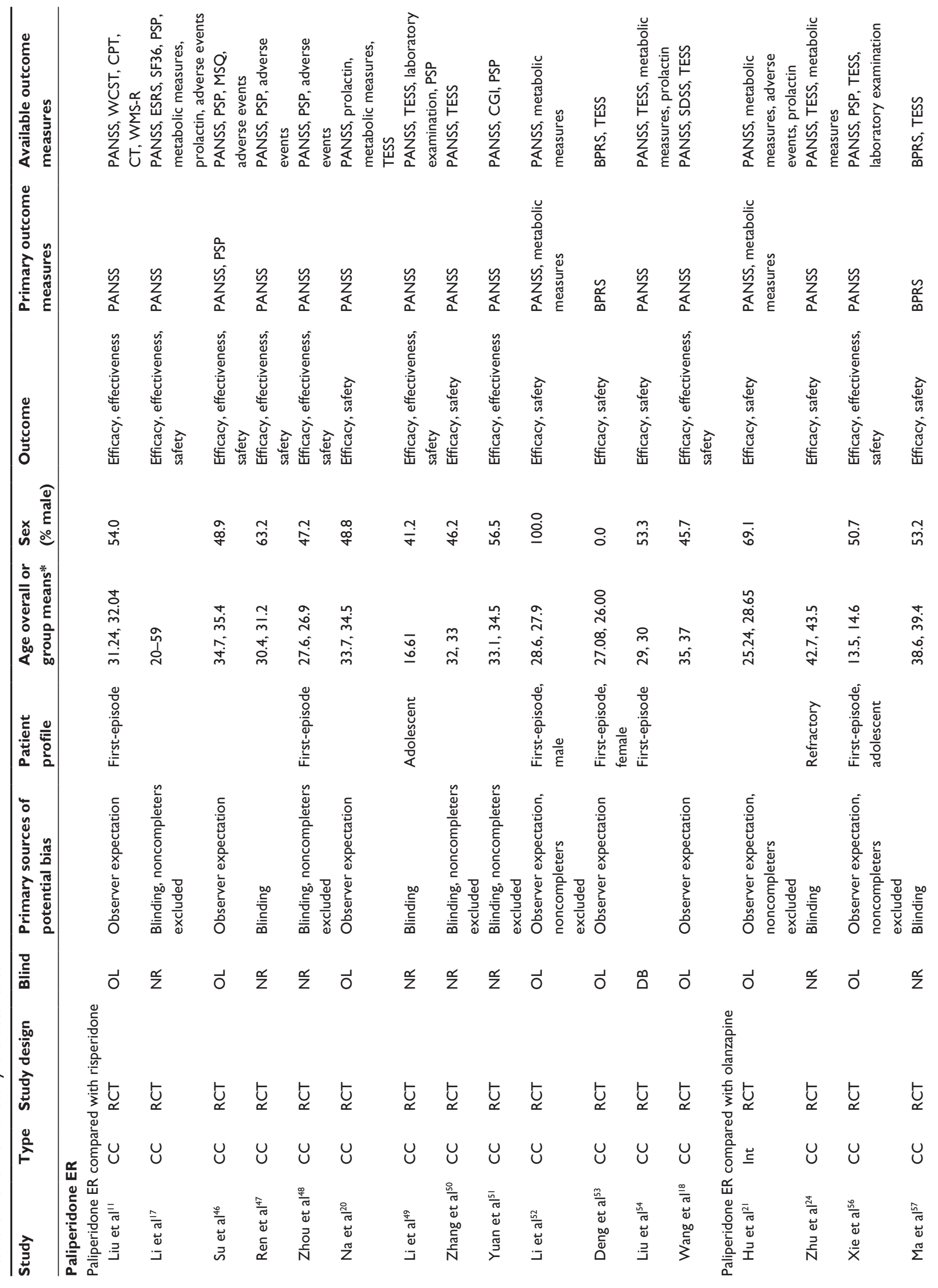




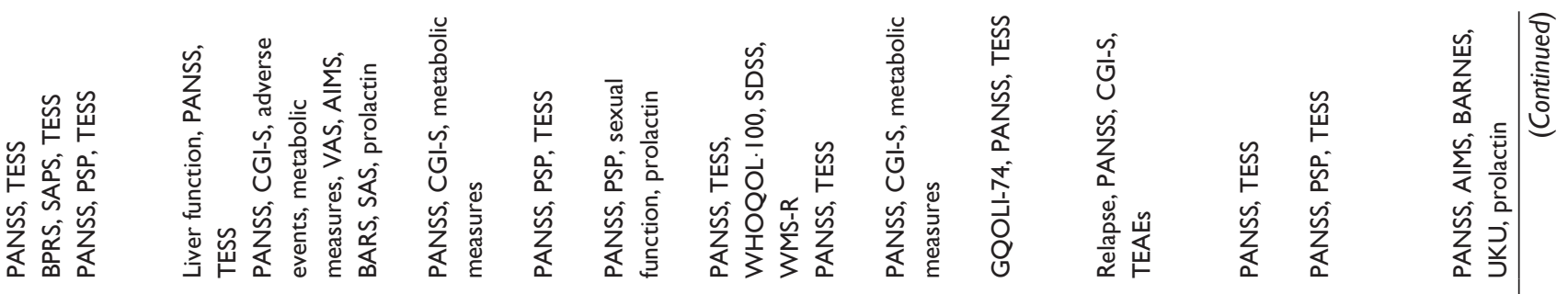

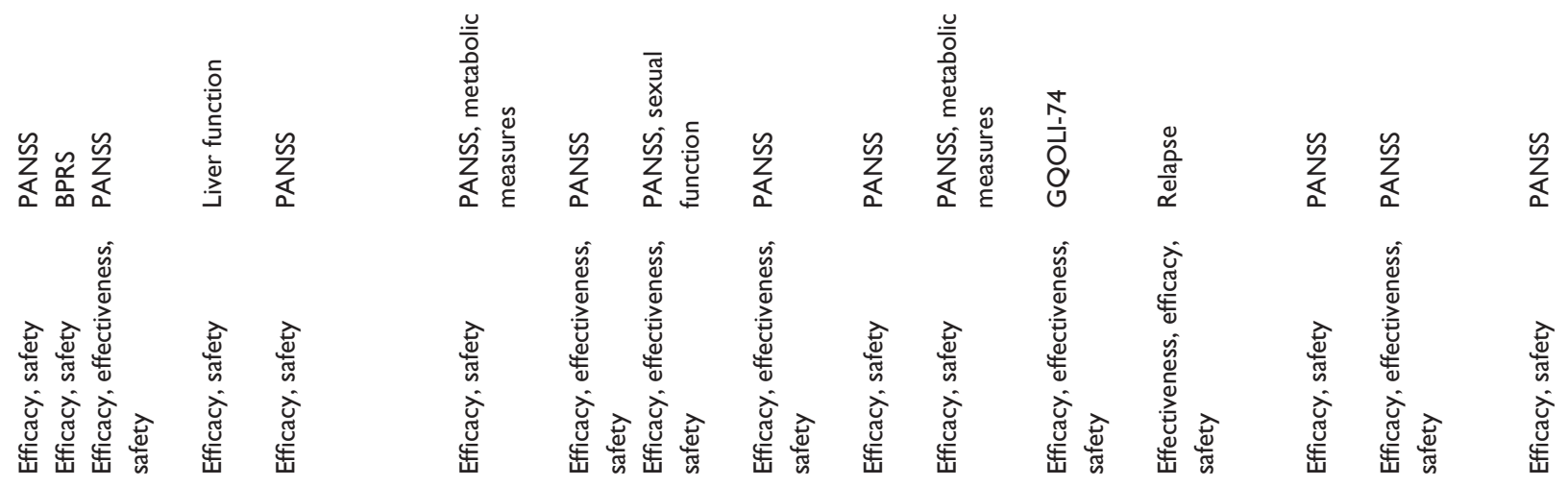

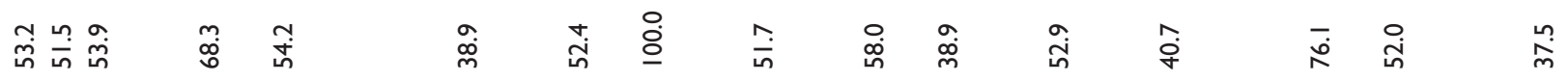

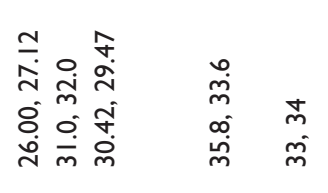
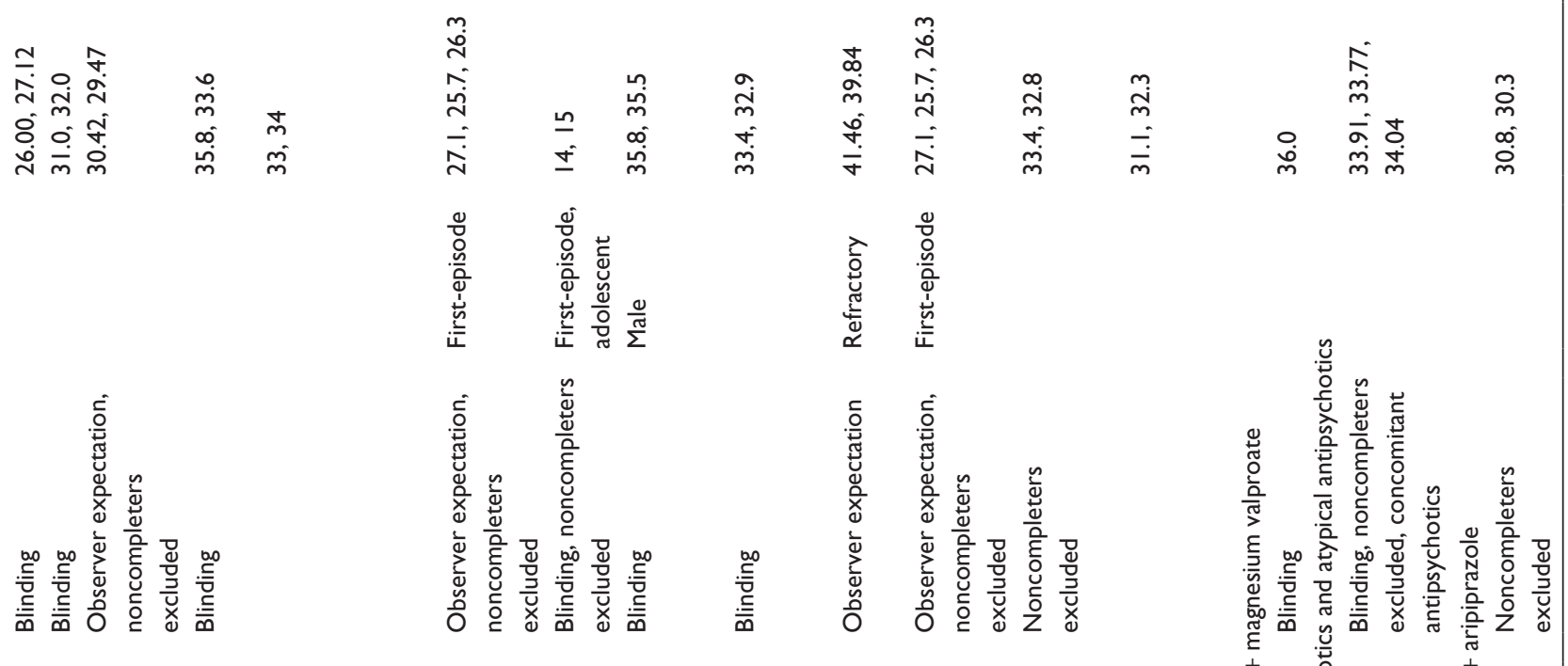

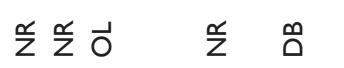

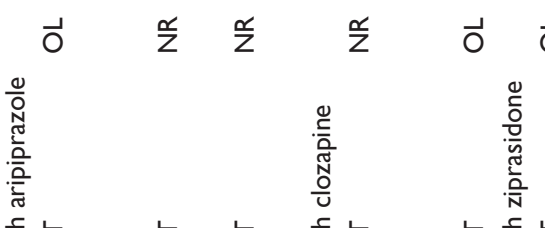

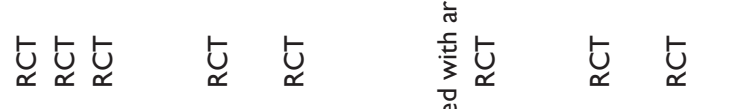

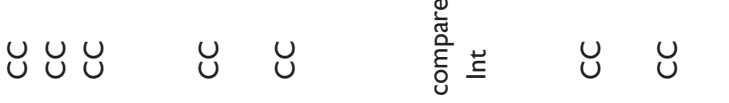

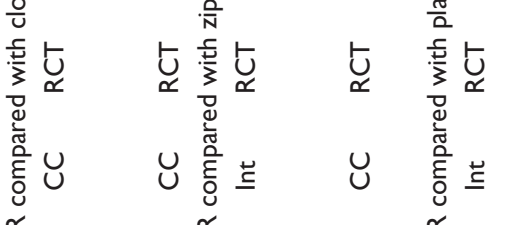

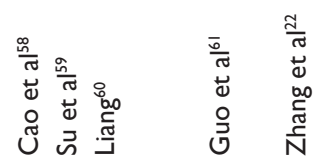

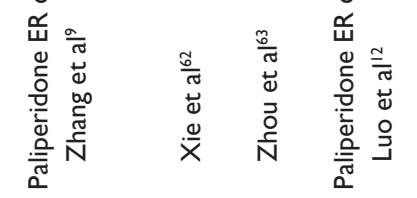

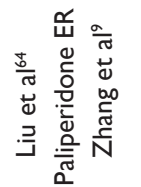
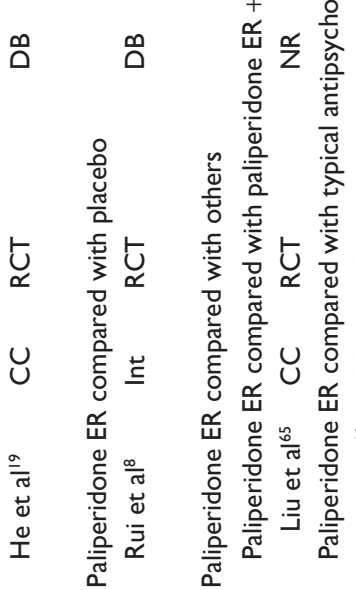

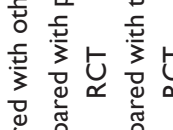

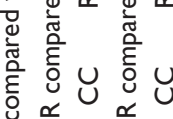

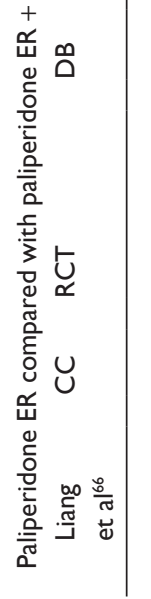




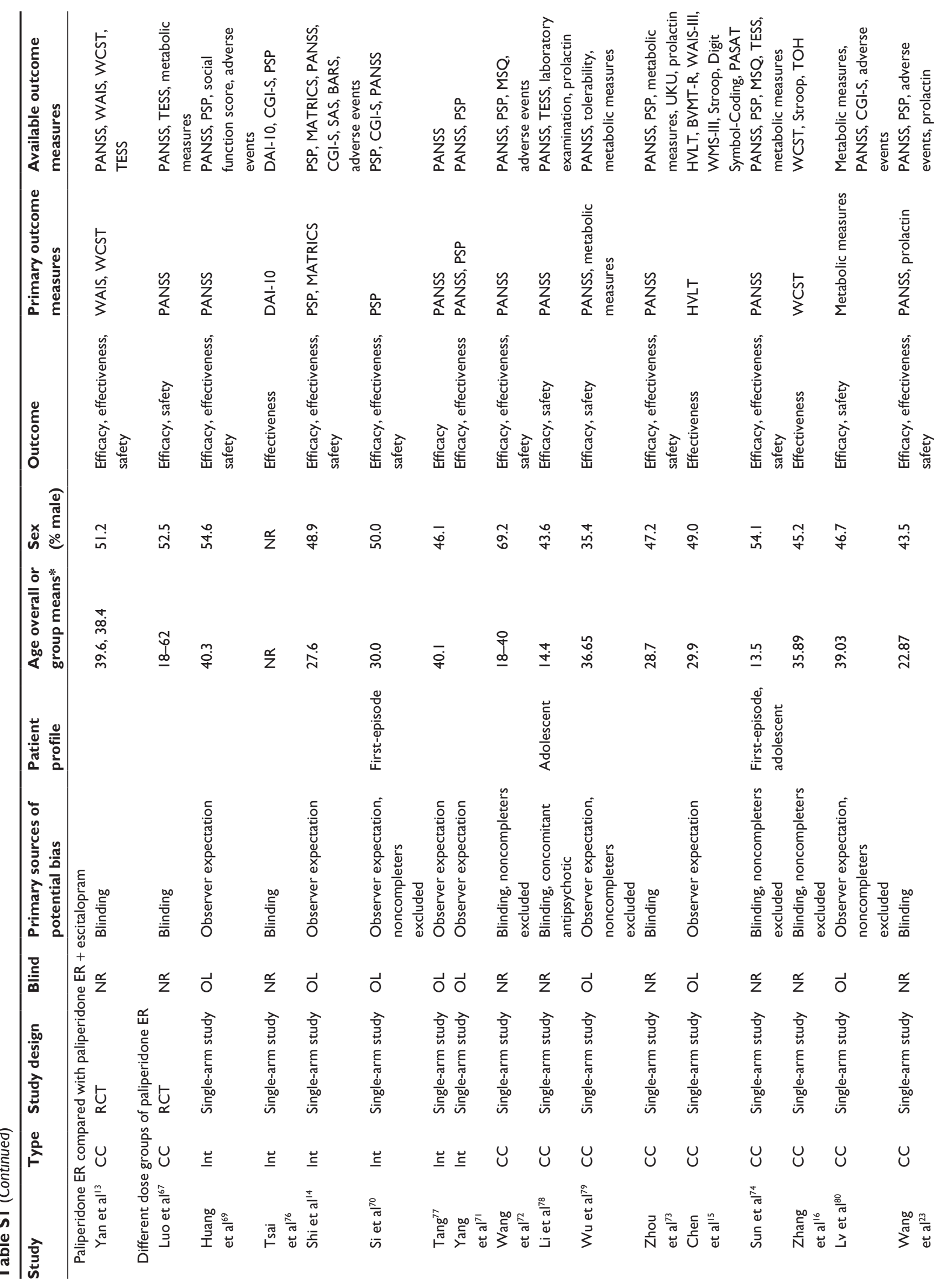




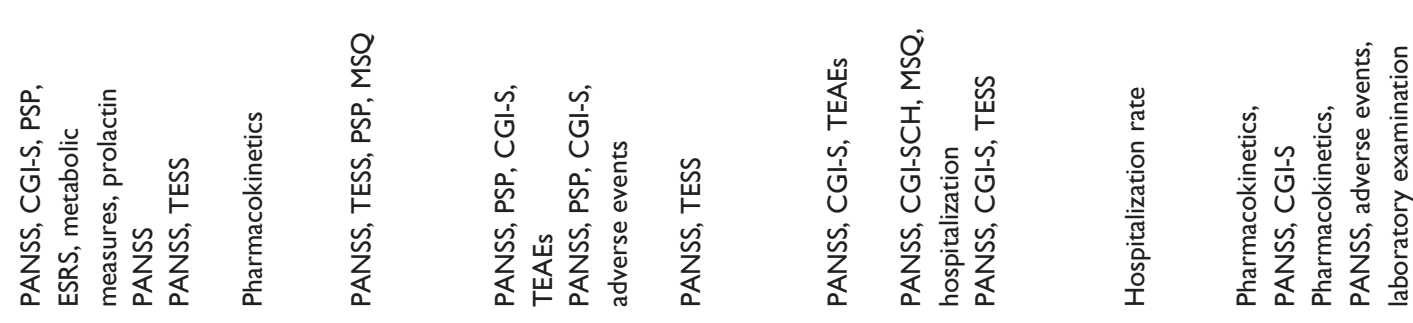

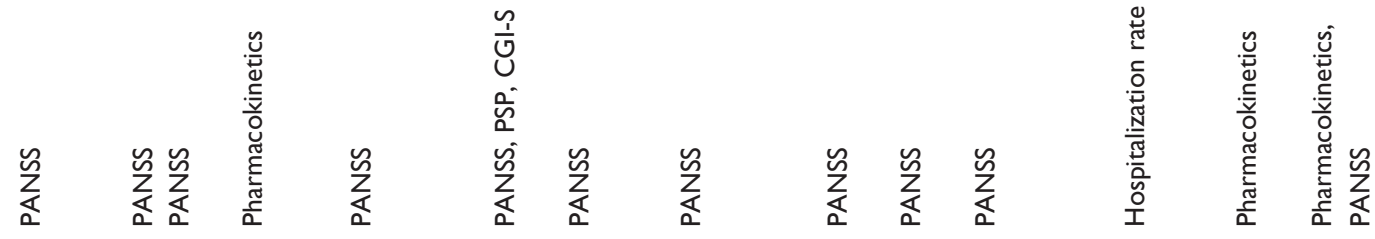

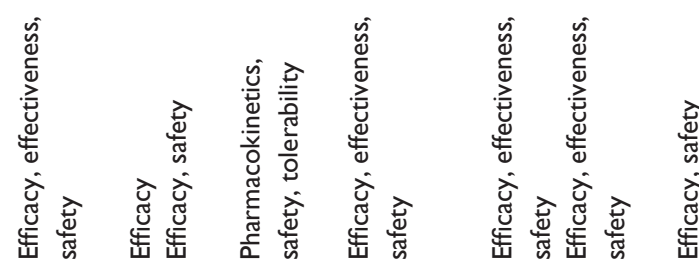

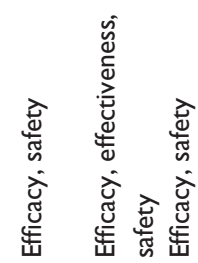

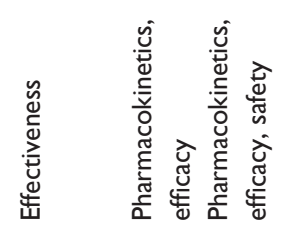

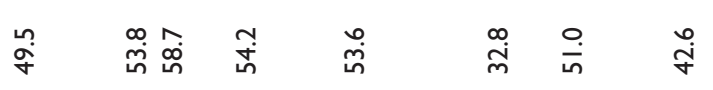

岗

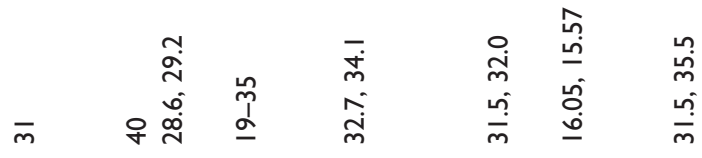

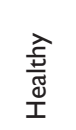

$\stackrel{4}{\Phi}$
$\stackrel{\mathscr{u}}{0}$
$\frac{0}{0}$

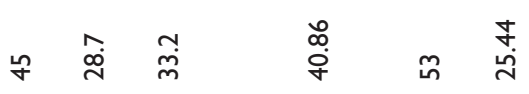

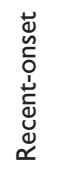

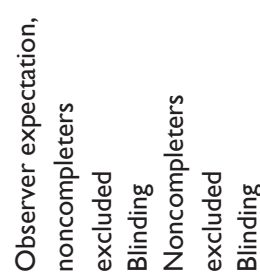
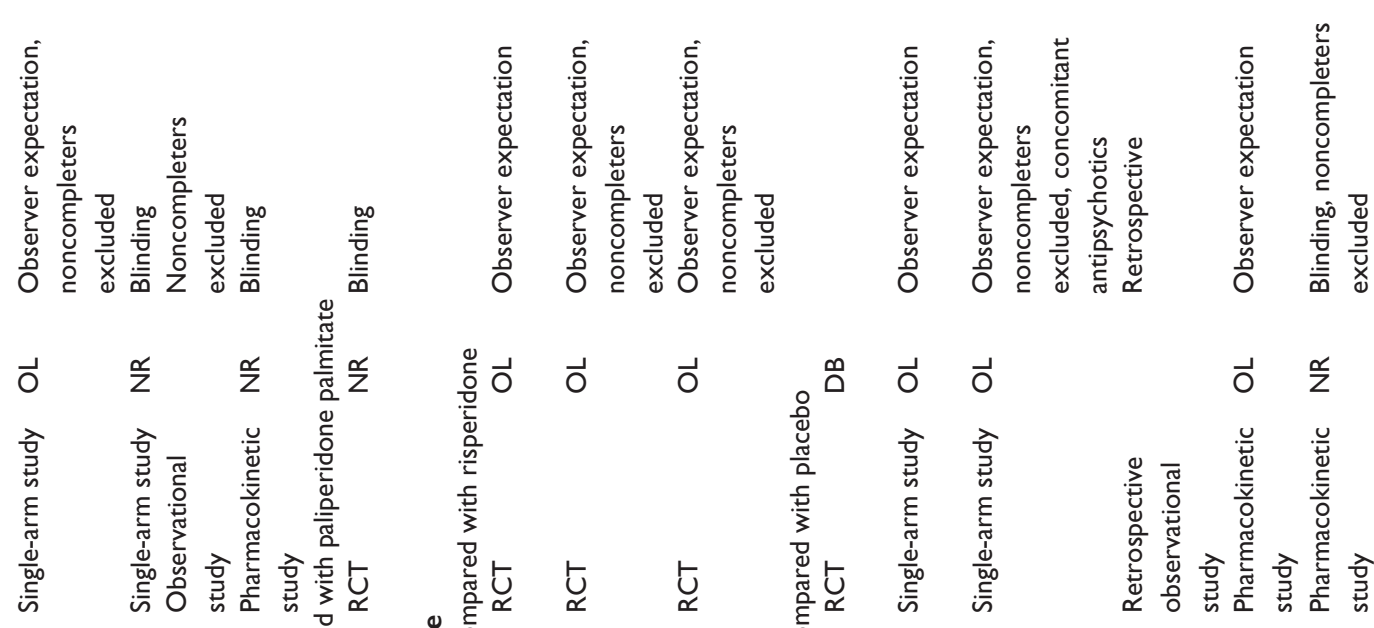

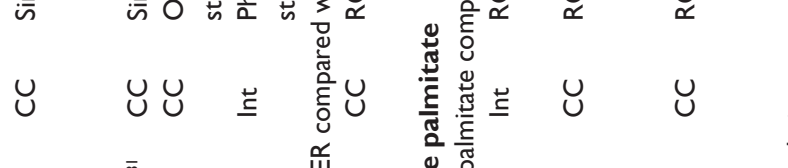

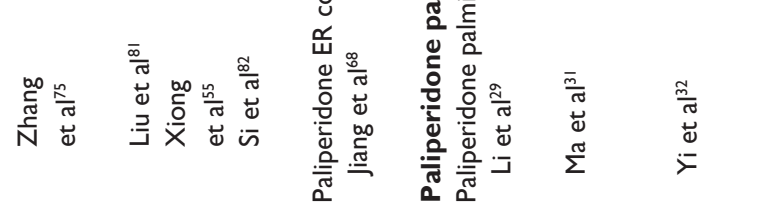
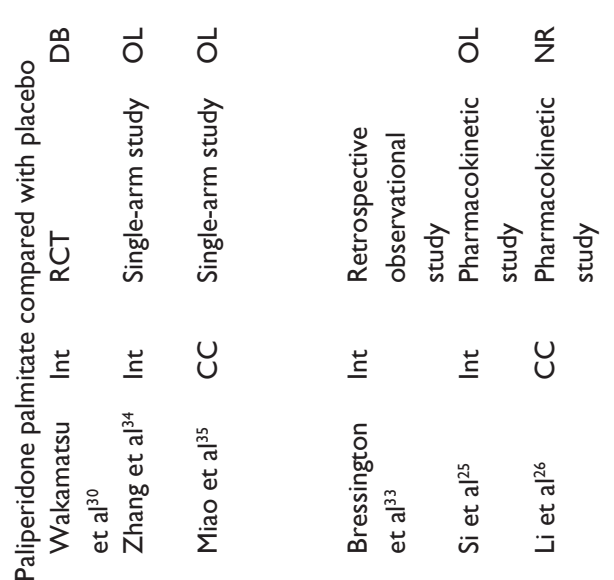

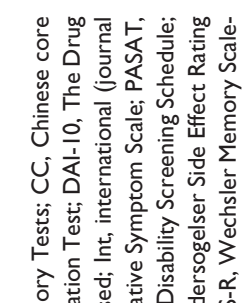

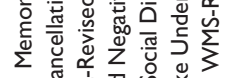

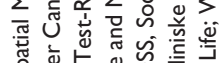

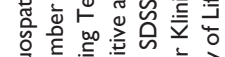

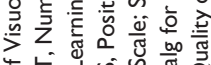

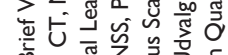

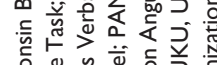

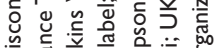

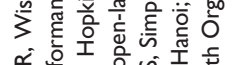

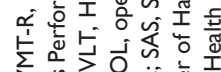

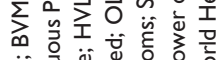

券

bo

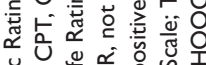

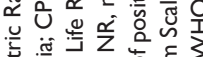

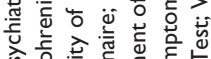

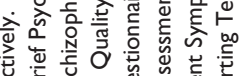

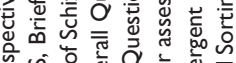

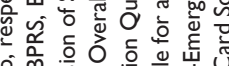

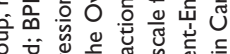

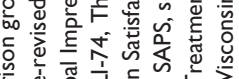

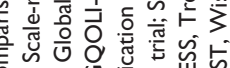

co

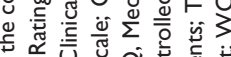

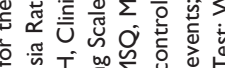

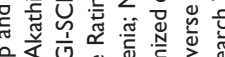

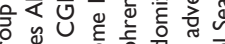

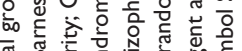

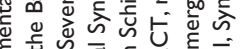

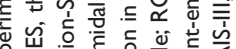

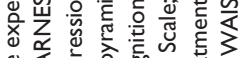

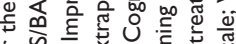

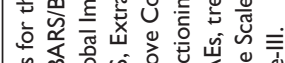

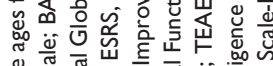

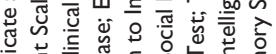

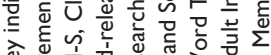

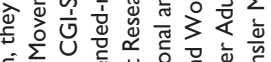

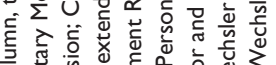

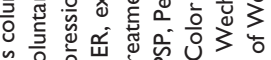

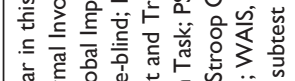

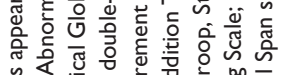

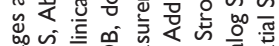

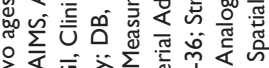

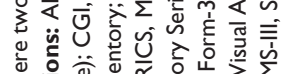

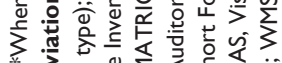

*

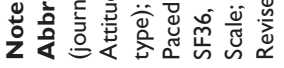




\section{References}

1. Liu M, Liu X, Miao X, Gao X. Effects of paliperidone extended-release tablets and risperidone on cognitive function in patients with firstepisode schizophrenia. Chinese Journal of New Drugs. 2012;21(04): 419-422.

2. Li C, Yang G, Chen H, et al. Eficacy, tolerability, quality of life and social functioning in schizophrenia patients after treatment with oral paliperidone extended-release tablets. Chinese Journal of New Drugs. 2012;21(12):1372-1376.

3. Su W, Li J, Yang J, Guan T, Na W. Effects of paliperidone on social functioning in schizophrenia patients; a randomized, opened, controlled trial. Chinese Journal of New Drugs and Clinical Remedies. 2012; 31(06):345-349.

4. Ren H, Li L. Clinical study on the efficacy of paliperidone extendedrelease tablets in the treatment of schizophrenia outpatients and its effect on social function. Chinese Journal of New Drugs. 2012;21(14): 1636-1638.

5. Zhou H, Wang S. Clinical efficacy of paliperidone in treatment of first episode schizophrenia. The Journal of Practical Medicine. 2012; 28(23):3986-3988.

6. Na W, Su W, Li J, et al. Comparison of paliperidone ER and risperidone in the treatment of schizophrenia. Chinese Journal of New Drugs. 2011;20(8):708-720.

7. Li X, Pan L, Jin G, Han X. The efficacy and safety of paliperidoneextended release capsules on treating adolescent schizophrenia. Shandong Medical Journal. 2011;51(15):96-97.

8. Zhang H, Liang W, Guo S. Comparision of eficacy and safety between Paliperidone and risperidone in patients with schizophrenia. Chinese Journal of New Drugs and Clinical Remedies. 2011;30(7):517-521.

9. Yuan T, Qin L, Yao M, Tang J, Yue W. Effects of paliperidone extendedrelease tablets on the personal and social functions in acute patients with schizophrenia. The Chinese Journal of Clinical Pharmacology. 2011; 27(09):672-675.

10. Li L, Li J, Yang J, Dai X, Su W, Yu B. A Comparative Study of the Effects of Paliperidone and Risperidone on the Glucose and Lipid Metabolism in First-Episode Male Schizophrenia Patients. Chinese Pharmaceutical Journal. 2013;48(8):649-651.

11. Deng X, Yang Y, Wang Q, Yin L. The comparison study on efficacy and safety of paliperidone extended-release and risperidone on female, first-episode schizophrenia patients. Chinese journal of nervous and mental disease. 2013;39(6):355-358.

12. Liu J, Yang J, Yang S, Chen Z. The efficacy and safety of paliperidone extended-release tablets for first-episode schizophrenia. The Journal of Practical Medicine. 2010;26(20):3775-3777.

13. Wang $\mathrm{Y}, \mathrm{Li} \mathrm{W}, \mathrm{Gu} \mathrm{D}$, et al. Eflicaey of paliperidone extended-release tablets in the improvement of social functions in schizophrenics: a randomized and controlled study. National Medical Journal of China. 2010; 90(29):2030-2035.

14. Hu S, Yao M, Peterson BS, et al. A randomized, 12-week study of the effects of extended-release paliperidone (paliperidone ER) and olanzapine on metabolic profile, weight, insulin resistance, and $\beta$-cell function in schizophrenic patients. Psychopharmacology. 2013;230(1):3-13.

15. Zhu Q, Pi J. A comparative study of paliperidone and olanzapine in the treatment of treatment-refractory schizophrenia. Chinese Journal of New Drugs. 2012;21(6):666-669.

16. Xie Q, Feng S, Zeng H, Xu Y, Wang J. Eficacies of paliperidone extended-release tablets and olanzapine for treating schizophrenia in children and adolescents. Chinese Journal of New Drugs. 2012;21(16): 1916-1919.

17. Ma Q, Li L, Lian H. A controlled comparison study on paliperidone extended-release tablets and olanzapine in the treatment of schizophrenia. Chinese Journal of New Drugs. 2012;21(22):2658-2661.

18. Cao G, Xie G. Observation of efficacy and safety of paliperidone sustained release tablets and domestic olanzapine in treatment of schizophrenia. Chongqing Medicine. 2011;40(17):1695-1696.
19. Su H, Fu W, Li D, Li Q, Chen J. Comparative study for treatment with Paliperidone release tablets and Olanzapine in schizophrenia. Chongqing Medicine. 2011-09-30 2011;40(27):2751-2753.

20. Liang Y. A clinical comparative study on paliperidone ER in treating acute phase schizophrenia patients. Chinese Journal of New Drugs. 2011; 20(24):2442-2445.

21. Guo X, Wang G, Wang Z, Wang N. The effects of paliperidone extended-release tablets and olanzapine on the liver function of patients with schizophrenia. Chinese Journal of New Drugs. 2014;23(16): 1941-1945.

22. Zhang H, Li H, Wang G, et al. The efficacy and safety of flexible doses of paliperidone extended-release tablets in the treatment of acute schizophrenia: a randomized, double blind olanzapine-controlled study. Chinese Journal of Psychiatry. 2009;42(3):153-157.

23. Zhang Y, Dai G. Efficacy and metabolic influence of paliperidone ER, aripiprazole and ziprasidone to patients with first-episode schizophrenia through 52 weeks follow-up in China. Human Psychopharmacology: Clinical and Experimental. 2012;27(6):605-614.

24. Xie Q, Tang J, Zhou L, Zeng H. A controlled clinical study between paliperidone and aripiprazole in adolescents first-episode schizophrenia. Chinese Journal of New Drugs and Clinical Remedies. 2013;32(1): $51-55$.

25. Zhou H, Wang S, Li Y, et al. Therapeutic efficacy of paliperidone in the treatment of male patients with schizophrenia and its effects on sexual function. Chinese Journal of Hospital Pharmacy. 2013;33(04): 308-311.

26. Luo S, Sun Q, Zeng D. The effects of paliperidone extended-release and clozapine on the life quality of schizophrenia patients. Journal of Practical Medicine. 2012;28(06):986-988.

27. Liu M, Liu X, Zhang N. A comparative study on efficacy and safety of paliperidone extended-release tablets and clozapine in treatment of resistant schizophrenia. Chinese Journal of New Drugs. 2012;21(14): 1639-1642.

28. He J, Tao Y, Long S, Zhou J. Influence of Paliperidone ExtendedRelease Tablets on the Social Function and Quality of Life in Patients with Schizophrenia. Journal of Chinese Pharmacy. 2012;47(13): 1090-1093.

29. Rui Q, Wang Y, Liang S, et al. Relapse prevention study of paliperidone extended-release tablets in Chinese patients with schizophrenia. Progress in Neuro-Psychopharmacology and Biological Psychiatry. 2014;53(2014):45-53.

30. Liu Z, Sun Y, Wang L. The efficacy of Magnesium Valproate combined with paliperidone on treating 23 schizophrenia patients. Shandong Medical Journal. 2011;51(23):54-55.

31. Liu Z, Zheng Y, Zheng T, An L. Efficacy of paliperidone extendedrelease tablets on improving social function in acute patients with schizophrenia. Journal of Shandong University (Health Science). 2011;49(8):100-103.

32. Liang J, Yan J, Zhang X. Aripirazole reduces paliperidone-induced increase of prolactin in patients with schizophrenia: a randomized, double blind and placebo-controlled study. Chinese Journal of New Drugs. 2014;23(11):1300-1310.

33. Yan D, Zhou L, Ma X, Deng X, Zhang X. The effects of paliperidone combined with Escitalopram on the cognitive functions and negative symptoms of schizophrenia patients. Chinese Journal of Prevention and Control of Chronic Diseases. 2014;22(04):481-483.

34. Luo R, Chen R. Clinical efficacy and safety of paliperidone extendedrelease tablets in different dosage groups in the treatment of schizophrenia. Chinese Journal of New Drugs. 2012;21(18):2193-2195.

35. Huang M, Yang T, Ten P, Liu I, Chiu W, Li C. Effects of paliperidone extended release on the symptoms and functioning of schizophrenia. BMC Clinical Pharmacology. 2012;12:1.

36. Tsai J, Lin W, Lung F. Social Interaction and Drug Attitude Effectiveness in Patients with Schizophrenia. Psychiatric Quarterly. 2011; 82(4):343-351. 
37. Shi C, Yu X, Kang L, et al. Paliperidone ER treatment and the improvement of social and cognitive function in patients with schizophrenics - A 24-week, single arm, open-label study. Schizophrenia Research. 2014; 153 Suppl 1(S118).

38. Si T, Tan Q, Zhang K, Wang Y, Rui Q. An open-label, flexible-dose study of paliperidone extended-release in chinese patients with firstonset psychosis. Neuropsychiatric Disease and Treatment. 2015;11: 87-95.

39. Tang T. Efficacy of paliperidone ER treatment in subjects with schizophrenia previously unsuccessfully treated with other oral antipsychotics. International Journal of Neuropsychopharmacology. 2010;13 Suppl 1(107).

40. Yang T, Huang M. Correlation between PANSS and personal and social performance (PSP) improvements in patients with schizophrenia by paliperidone ER treatment. International Journal of Neuropsychopharmacology. 2010;13 Suppl 1(112).

41. Wang H, Wang G, Wang H, Shu C, Bai X, Shu Y. Clinical efficacy and patient satisfaction evaluation in acute schizophrenia with paliperidone extended release therapy. Medical Journal of Wuhan University. 2012;33(2):259-262.

42. Li L, Liu J, Qian Q, Yang W, Qi J. Efficacy and safety of paliperidone ER in the treatment of child and adolescent inpatients with schizophrenia in a natural state and the clinical recommendation. Chinese Journal of New Drugs. 2012;21(6):661-665.

43. Wu F, Ning Y, Li Z, Lu W. Efficacy of extended release paliperidone at flexible-dose and its influence on glucose and lipid metabolism in patients with acute schizophrenia. Chinese Journal of New Drugs. 2012; 21(7):772-775.

44. Zhou H, Chen F, Lu Z, et al. Efficacy and safety of flexible-dose oral paliperidone extended-release tablets in the treatment of acute schizophrenia. Chinese Journal of New Drugs. 2012;21(12):1367-1371.

45. Chen F, Zhou H, Lu Z, et al. Cognitive effect of flexible-dose oral paliperidone extended-release tablets in treating acute schizophrenia. Chinese Journal of New Drugs. 2012;21(19):2297-2301.

46. Sun L, Zhou T, Lei T. Efficacy and safety of paliperidone ER in the treatment of adolescent patients with first-episode schizophrenia. Chinese Journal of New Drugs. 2011;20(09):799-802.

47. Zhang Y, Lei J, Hu Y. Effects of paliperidone on executive functions of schizophrenia patients. Modern Preventive Medicine. 2013;40(18): 3448-3450.

48. Lv J, Di X, Niu Y, Li J, Yang F. Effect of paliperidone extended-release tablets on blood glucose, blood lipids and body weight of patients with acute schizophrenia. Chinese Journal of New Drugs. 2013;22(20): 2405-2409.

49. Wang Z, Wang G, Wang H, Wang X. Clinical efficacy of paliperidone controlled release tablets and its influence on serum prolactin level in patients with acute schizophrenia. Chinese Journal of New Drugs. 2009;18(21):2052-2055.
50. Zhang H, Hao X, Wang X, et al. An open-label study on the safety and efficacy of paliperidone extended-release in non-acute schizophrenic patients. Chinese Journal of Psychiatry. 2012;45(1):20-24.

51. Liu X, Huang S, Lin Z, Zheng Z, Chen X. Relationship between the dopamine D2 receptor gene polymorphism and efficacy of paliperidone extended release tablets. Chinese Journal of Clinical Pharmacology. 2014;30(9):767-769.

52. Xiong D, Wang Q, Tu J, Wang Y. Clinical Observation on Palipeddone Sustained Release Tablet in the Treatment of Schizophrenia in Outpatient. China Pharmacy. 2010;21(18):1681-1682.

53. Si T, Shu L, Liu Y, Su Y. Single-dose pharmacokinetics of paliperidone extended-release tablets in healthy Chinese subjects. Human Psychopharmacology. 2010;25(5):404-409.

54. Jiang J, Li X, Tang C, Zhang J. The efficacy and safety of paliperidone palmitate versus paliperidone extended-release on patients with schizophrenia. Guangdong Medical Journal. 2014;35(9):1414-1416.

55. Li H, Rui Q, Ning X, Xu H, Gu N. A comparative study of paliperidone palmitate and risperidone long-acting injectable therapy in schizophrenia. Progress in Neuro-Psychopharmacology and Biological Psychiatry. 2011;35(4):1002-1008.

56. Ma J, Li Y, Xu H, et al. Efficacy and safety of paliperidonepalmitate injection in the treatment of schizophrenia in teenagers. Chinese Journal of New Drugs. 2014;23(8):972-976.

57. Yi F, Liu X, Zhen L. Efficacy and safety of paliperidone palmitate injection in treatment of acute schizophrenia. Chinese Journal of New Drugs and Clinical Remedies. 2013;32(12):988-992.

58. Wakamatsu A, Takahashi N, Takahashi M, et al. Efficacy and safety of paliperidone palmitate in Asian patients with schizophrenia: A 13-week double-blind study. European Neuropsychopharmacology. 2013; 23 Suppl 2.

59. Zhang F, Si T, Chiou C, et al. Efficacy, safety, and impact on hospitalizations of paliperidone palmitate in recent-onset schizophrenia. Neuropsychiatric Disease and Treatment. 2015;11:657-668.

60. Miao X, Wang Q, Liu L, Bai L. An open-label study on the efficacy of paliperidone palmitate in patients with acute schizophrenia. Chinese Journal of New Drugs. 2014;23(19):2280-2283.

61. Bressington D, Stock J, Hulbert S, MacInnes D. A retrospective observational study of the effectiveness of paliperidone palmitate on acute inpatient hospitalization rates. International Clinical Psychopharmacology. 2015;30(4):230-236.

62. Si T, Su Y, Liu Y, et al. Pharmacokinetics and tolerability of paliperidone palmitate injection in Chinese subjects. Human Psychopharmacology: Clinical and Experimental. 2014;29(2):203-210.

63. Li D, Mi W, Li L, Wang Z, Wang Y, Zhang H. Plasma concentrations of intramuscular paliperidone palmitate and the relationship between the dose and clinical safety. Chinese Journal of Clinical Pharmacology. 2012;28(8):563-565.
Neuropsychiatric Disease and Treatment

\section{Publish your work in this journal}

Neuropsychiatric Disease and Treatment is an international, peerreviewed journal of clinical therapeutics and pharmacology focusing on concise rapid reporting of clinical or pre-clinical studies on a range of neuropsychiatric and neurological disorders. This journa is indexed on PubMed Central, the 'PsycINFO' database and CAS,

\section{Dovepress}

and is the official journal of The International Neuropsychiatric Association (INA). The manuscript management system is completely online and includes a very quick and fair peer-review system, which is all easy to use. Visit http://www.dovepress.com/testimonials.php to read real quotes from published authors. 